IJRMMS-D-15-00139 - edited and approved by editor

\title{
Three-Dimensional Poroelastic Modeling of Injection Induced Permeability Enhancement and Microseismicity
}

\author{
Reza Safari ${ }^{\mathrm{a}}$, Ahmad Ghassemi ${ }^{\mathrm{b}^{*}}$ \\ Mewbourne School of Petroleum and Geological Engineering, University of Oklahoma, \\ Norman, Oklahoma, USA \\ * Corresponding Author \\ ahmad.ghassemi@ou.edu \\ 100 E. Boyd Street, SEC 1210, Mewbourne School of Petroleum and Geological Engineering, \\ The University of Oklahoma, Norman, Oklahoma, USA
}

\begin{abstract}
A combined boundary element/finite element numerical method is employed to investigate the response of a hydraulic fracture/natural fracture network to injection. The model is threedimensional and poroelastic. It considers the effects of fracture interactions, fluid diffusion into the matrix and the natural fractures, fracture opening and shear dilation. The natural fractures behavior is modeled using non-linear deformation in both shear and normal directions. For the shear mode, the slip-weakening model is used to simulate the post-shear failure behavior of the fractures. An example simulation is carried out to study the response of a fracture network to injection. The calculated injection pressure profile is used to ascertain the deformation response of the fracture network and its permeability enhancement. The simulation results clearly illustrate the potential for induced microseismicity due to permanent shear slip on natural fractures surrounding a hydraulically driven major fracture. Although the slip on the natural fractures can potentially contribute to seismic activity, its contribution to permeability enhancement depends on whether or not they propagate to connect to form a "hydraulically" connected network with the main fracture. When the natural fracture system is not connected to the main flow path, the MEQ information may overestimate the so-called stimulated reservoir volume.
\end{abstract}


Keywords: Hydraulic stimulation, displacement discontinuity, slip weakening, microseismicity, stimulated reservoir volume 


\section{Introduction}

Enhanced Geothermal Systems (EGS) [1] and the extraction of hydrocarbons from low permeability reservoirs rely on generating a permeable fracture network [2]. Numerical modeling is a suitable tool to design and analyze the stimulation processes of the fracture network. It is extremely essential to utilize a modeling technique that encompasses the major affective mechanisms accurately. Early models of fracture analyses $[3,4]$ relied on elastic twodimensional analytical models of single fractures and ignored the poroelastic effects. Later on, the generation of a fracture network during the injection into unconventional reservoirs has been recognized [5-9]. However, these models underscored the need to fully coupled fracture network behavior to injection/extraction processes. Recent models, explicitly consider the effect of fracture network in the two dimensional fully coupled analysis [10-11]. In this paper a three dimensional (3D) fully coupled poroelastic model is presented and used to simulate injection into a network of fractures. The model uses the poroelastic displacement discontinuity (DD) to simulate fractures and the finite element method to model fluid flow inside fractures. The DD is based on improving the development of Zhou and Ghassemi [12] to consider multiple nonlinear elastic rock joints, slip-weakening behavior after permanent slippage, shear dilation and its effect on the fracture permeability enhancement, and transition of joint fractures (i.e. crack surfaces are in contact condition) to hydraulic fractures (i.e. crack surfaces are separated from each other).

\section{Governing equations}

\subsection{Constitutive relations for rock matrix}

The constitutive behavior of fluid-saturated rocks is described by the linear theory of poroelasticity $[13,14]$. The coupled equations for deformation and fluid diffusion in porous rock under isothermal conditions can be found in Rice and Cleary [14]. The equations present the relationship among the volumetric response of porous rock, pore pressure variations, and changes in the pore pressure in response to an applied mean stress. Besides, pore-fluid diffusion relationship can be presented by Darcy's law $[13,14]$. By combining these relations and the 
equilibrium and compatibility conditions, three-dimensional field equations (Navier's equations with pore pressure coupling) can be presented as follow:

$$
\begin{aligned}
& G \nabla^{2} u_{i}+\frac{G}{1-2 v} u_{k, k i}-\alpha \nabla p=0 \\
& \frac{\partial p}{\partial t}-\frac{2 k G B^{2}(1-2 v)\left(1+v_{u}\right)^{2}}{9 \mu\left(v_{u}-v\right)\left(1-2 v_{u}\right)} \nabla^{2} p=-\frac{2 G B\left(1+v_{u}\right)}{3\left(1-2 v_{u}\right)} \frac{\partial \varepsilon}{\partial t}
\end{aligned}
$$

where $G$ is the rock shear modulus, $u_{i}$ is the rock displacement component in " $i$ " direction, $v$ is drained Poisson's ratio, $v_{u}$ is un-drained Poisson's ratio, $\alpha$ is Biot's coefficient, $p$ is pore pressure, $t$ is time, $k$ is rock permeability, $B$ is Skempton's coefficient, $\mu$ is pore fluid viscosity, and $\varepsilon$ is the volumetric strain. Equations (1) should be solved with the appropriate boundary and initial conditions.

\subsection{Fluid flow inside fractures}

A fracture is represented as a parallel plate model. The separation $(W)$ between the plates is assumed constant for a representative element of the fracture. This particular fracture geometry is amenable to an exact solution of the Stokes equation [15]. The solution for steady state, laminar incompressible flow is known as the Cubic law, $Q=W^{3} / 12 \mu \nabla p$, where $\mathrm{Q}$ is the volumetric flow rate and $\nabla \mathbf{p}$ is the pressure gradient applied to the fluid. Using Darcy's Law, an expression for parallel plate permeability $\left(k_{f}\right)$, in units of length ${ }^{2}$, is obtained: $k_{f}=W^{2} / 12 \mu$.

Assuming isothermal conditions, mass transfer in fracture system includes fluid flow within the fracture and leak-off into the reservoir matrix. It is also assumed that the cubic law is valid in the fracture. By taking into account that the fracture aperture is variable over time, mass continuity equation can be presented as follows:

$$
\nabla(W \times \mathbf{v})=-2 v_{l}+Q_{i n j}(t) \delta\left(\mathbf{x}_{i n j}\right)-Q_{e x t}(t) \delta\left(\mathbf{x}_{e x t}\right)-\frac{\partial W}{\partial t}
$$

where $W$ is fracture opening, $\mathbf{v}$ is the fracturing fluid velocity vector, $v_{l}$ is leak-off from one surface of fracture into rock matrix, $Q_{i n j}(t)$ is the injection rate, $Q_{e x t}(t)$ is the production rate, 
$\delta\left(\mathbf{x}_{i n j}\right)$ and $\delta\left(\mathbf{x}_{e x t}\right)$ are the functions that are zero everywhere except at $\mathbf{x}_{i n j}$ and $\mathbf{x}_{e x t}$ which are the location of injection and extraction wells accordingly. The governing equation for fluid flow inside fracture system is derived by substituting the fluid mass continuity equation (2) into the Cubic law:

$$
\nabla\left(\frac{W^{3}}{12 \mu} \nabla p\right)=\left\{\frac{\partial W}{\partial t}-Q_{i n j}(t) \delta\left(\mathbf{x}_{i n j}\right)+Q_{e x t}(t) \delta\left(\mathbf{x}_{e x t}\right)+2 v_{l}\right\}
$$

in which the fluid pressure on the fracture surface, the fracture aperture, and leakoff from the fracture surface into the rock matrix are unknown. These unknowns should to be calculated during solution procedure for a given history of injection and extraction rates.

\section{Numerical implementation}

\subsection{Discretization of principal relations}

To analyze a fracture system during an arbitrary injection or extraction period, partial differential equations (1) and (3) should be solved simultaneously with corresponding boundary and initial conditions. These two equations are coupled via the fluid pressure inside fracture and fracture aperture.

Governing equation (1) with an infinite boundary, fracture surface boundary, and initial in-situ condition is solved numerically using a discontinuity technique. In the discontinuity method, fractures are considered as surfaces across which normal and two shear displacement components and fluid flux are discontinuous. Hence, the stresses and pore pressure distributions in the field depend on the quantity of discontinuities on the fracture surface as well as the corresponding in-situ stresses and pore pressure. By invoking the poroelastic displacement discontinuity technique $[16,17]$, the stresses and pressure at any point can be evaluated using the strengths of the DDs, fluid flux discontinuities, and in-situ stresses and pressure: 


$$
\begin{aligned}
& \sigma_{i j}\left(\mathbf{x}, t_{n}\right)=\int_{0}^{t_{n}} \int_{A}\left\{\sigma_{i j k n}^{i d}\left(\mathbf{x}-\chi, t-t^{\prime}\right) \times D_{k n}\left(\chi, t^{\prime}\right)+\sigma_{i j}^{i s}\left(\mathbf{x}-\chi, t-t^{\prime}\right) \times D_{f}\left(\chi, t^{\prime}\right)\right\} d A(\chi) d t^{\prime}+\sigma_{i j}(\mathbf{x}, 0) \\
& p\left(\mathbf{x}, t_{n}\right)=\int_{0}^{t_{n}} \int_{A}\left\{p_{i j}^{i d}\left(\mathbf{x}-\chi, t-t^{\prime}\right) \times D_{i j}\left(\chi, t^{\prime}\right)+p^{i s}\left(\mathbf{x}-\chi, t-t^{\prime}\right) \times D_{f}\left(\chi, t^{\prime}\right)\right\} d A(\chi) d t^{\prime}+p(\mathbf{x}, 0)
\end{aligned}
$$

where $\sigma_{i j}\left(\mathbf{x}, t_{n}\right)$ is the "ij" component of stress tensor at point $\mathbf{x}$ and time $t_{n}, p\left(\mathbf{x}, t_{n}\right)$ is the pore pressure at point $\mathbf{x}$ and time $t_{n}, A$ is cracks surface, $\sigma_{i j k n}^{i d}\left(\mathbf{x}-\chi, t-t^{\prime}\right)$ represents induced instantaneous "ij" stress components at time $t$ and location $\mathbf{x}$ due to unit instantaneous DD in "kn" directions occurring at time $t^{\prime}$ and location $\chi, D_{k n}\left(\chi, t^{\prime}\right)$ is the strength of instantaneous DD in " $k n$ " directions at time $t^{\prime}$ and location $\chi, \sigma_{i j}^{i s}\left(\mathbf{x}-\chi, t-t^{\prime}\right)$ is induced instantaneous "ij" stress components at time $t$ and location $\mathbf{x}$ due to unit instantaneous fluid source at time $t^{\prime}$ and location $\chi, D_{f}\left(\chi, t^{\prime}\right)$ represents the strength of instantaneous fluid source (equal to $2 v_{l}$ ) at time $t^{\prime}$ and location $\chi, p_{i j}^{i d}\left(\mathbf{x}-\chi, t-t^{\prime}\right)$ denotes induced pore pressure at time $t$ and location $\mathbf{x}$ due to unit instantaneous DD in " $\mathrm{kn}$ " direction occurring at time $t$ ' and location $\chi, p^{i s}\left(\mathbf{x}-\chi, t-t^{\prime}\right)$ is the induced pore pressure at time $t$ location $\mathbf{x}$ due to unit instantaneous fluid source occurring at time $t^{\prime}$ at location $\chi, \sigma_{i j}(\mathbf{x}, 0)$ is ' $\mathrm{ij}$ ' component of in-situ stress tensor at location $\mathbf{x}, \quad p(\mathbf{x}, 0)$ is in-situ pore pressure at location $\mathbf{x}$.

To calculate the strength of DDs and the fluid source discontinuity (leakoff), eq. (4) is considered on the fracture surface (i.e. $\mathbf{x}$ is located on $A$ ) and the temporal integrals of the instantaneous fundamental solutions are expressed in terms of continuous fundamental solutions $[18,19]$. In this manner, temporal integration is circumvented. Moreover, by discretizing $t_{n}$ into "s" increments of $\Delta t$, representing the boundaries of all fractures by " $\mathrm{N}$ " quadrilateral four node elements, assuming constant DDs and linear variation of fluid source intensities across each element, the boundary integral eq. (4) can be re-written as: 


$$
\begin{aligned}
& \sigma_{33}\left(\mathbf{x}^{m}, s \Delta t\right)=\sum_{r=1}^{N}\left[S_{33 k 3}^{d c}\left(\mathbf{x}^{m}-\chi^{r}, \Delta t\right) \Delta D D_{k 3}^{r, s \Delta t}+\sum_{q=1}^{4}\left\{S_{33}^{s c}\left(\mathbf{x}^{m}-\boldsymbol{\chi}_{q}^{r}, \Delta t\right) \Delta f_{q}^{r, s \Delta t}\right\}\right]+ \\
& \sum_{\ell=0}^{s-1} \sum_{r=1}^{N}\left[S_{33 k 3}^{d c}\left(\mathbf{x}^{m}-\boldsymbol{\chi}^{r}, \ell \Delta t\right) \Delta D D_{k 3}^{r,(s-\ell) \Delta t}+\sum_{q=1}^{4}\left\{S_{33}^{s c}\left(\mathbf{x}^{m}-\boldsymbol{\chi}_{q}^{r}, \ell \Delta t\right) \Delta f_{q}^{r,(s-\ell) \Delta t}\right\}\right]+\sigma_{33}\left(\mathbf{x}^{m}, 0\right) \\
& \sigma_{13}\left(\mathbf{x}^{m}, s \Delta t\right)=\sum_{r=1}^{N}\left[S_{13 k 3}^{d c}\left(\mathbf{x}^{m}-\boldsymbol{\chi}^{r}, \Delta t\right) \Delta D D_{k 3}^{r, s \Delta t}+\sum_{q=1}^{4}\left\{S_{13}^{s c}\left(\mathbf{x}^{m}-\boldsymbol{\chi}_{q}^{r}, \Delta t\right) \Delta f_{q}^{r, s \Delta t}\right\}\right]+ \\
& \sum_{\ell=0}^{s-1} \sum_{r=1}^{N}\left[S_{13 k 3}^{d c}\left(\mathbf{x}^{m}-\boldsymbol{\chi}^{r}, \ell \Delta t\right) \Delta D D_{k 3}^{r,(s-\ell) \Delta t}+\sum_{q=1}^{4}\left\{S_{13}^{s c}\left(\mathbf{x}^{m}-\boldsymbol{\chi}_{q}^{r}, \ell \Delta t\right) \Delta f_{q}^{r,(s-\ell) \Delta t}\right\}\right]+\sigma_{13}\left(\mathbf{x}^{m}, 0\right) \\
& \sigma_{23}\left(\mathbf{x}^{m}, s \Delta t\right)=\sum_{r=1}^{N}\left[S_{23 k 3}^{d c}\left(\mathbf{x}^{m}-\boldsymbol{\chi}^{r}, \Delta t\right) \Delta D D_{k 3}^{r, s \Delta t}+\sum_{q=1}^{4}\left\{S_{23}^{s c}\left(\mathbf{x}^{m}-\boldsymbol{\chi}_{q}^{r}, \Delta t\right) \Delta f_{q}^{r, s \Delta t}\right\}\right]+ \\
& \sum_{\ell=0}^{s-1} \sum_{r=1}^{N}\left[S_{23 k 3}^{d c}\left(\mathbf{x}^{m}-\boldsymbol{\chi}^{r}, \ell \Delta t\right) \Delta D D_{k 3}^{r,(s-\ell) \Delta t}+\sum_{q=1}^{4}\left\{S_{23}^{s c}\left(\mathbf{x}^{m}-\boldsymbol{\chi}_{q}^{r}, \ell \Delta t\right) \Delta f_{q}^{r,(s-\ell) \Delta t}\right\}\right]+\sigma_{23}\left(\mathbf{x}^{m}, 0\right) \\
& p\left(\mathbf{x}_{p}^{m}, s \Delta t\right)=\sum_{r=1}^{N}\left[P_{k 3}^{d c}\left(\mathbf{x}_{p}^{m}-\boldsymbol{\chi}^{r}, \Delta t\right) \Delta D D_{k 3}^{r, s \Delta t}+\sum_{q=1}^{4}\left\{P^{s c}\left(\mathbf{x}_{p}^{m}-\boldsymbol{\chi}_{q}^{r}, \Delta t\right) \Delta f_{q}^{r, s \Delta t}\right\}\right]+ \\
& \sum_{\ell=0}^{s-1} \sum_{r=1}^{M}\left[P_{k 3}^{F c}\left(\mathbf{x}_{p}^{m}-\chi^{r}, \ell \Delta t\right) \Delta D D_{k 3}^{r,(s-\ell) \Delta t}+\sum_{q=1}^{4}\left\{P^{s c}\left(\mathbf{x}_{p}^{m}-\boldsymbol{\chi}_{q}^{r}, \ell \Delta t\right) \Delta f_{q}^{r,(s-\ell) \Delta t}\right\}\right]+p\left(\mathbf{x}_{p}^{m}, 0\right)
\end{aligned}
$$

where $\mathbf{x}^{m}$ and $\chi^{r}$ are the coordinates of centre of element " $m$ " and " $\mathrm{r}$ " correspondingly; $\mathbf{x}_{p}^{m}$ and $\chi_{q}^{r}$ are the coordinates of vertices " $\mathrm{p}$ " and " $\mathrm{q}$ " of element " $\mathrm{m}$ " and " $\mathrm{r}$ " correspondingly; $\Delta D D_{k n}^{r, s \Delta t}$ is the increment of " $\mathrm{kn}$ " component of a continuous DD at center of element " $\mathrm{r}$ " after time "s $\Delta \mathrm{t}$ "; $\Delta f_{q}^{r, s \Delta t}$ is the increment of total leak-off at vertex "q" of element "r" after time "s $\Delta \mathrm{t} " ; S_{i j k n}^{d c}, S_{i j}^{s c}, P_{i j}^{d c}$, and $P^{s c}$ are the continuous fundamental solution in local coordinates of each element which their relations can be found in $[18,19]$. In the equation $(5), S_{i j k n}^{d c}\left(\mathbf{x}^{m}-\boldsymbol{\chi}^{r}, \Delta t\right)$ is the "ij" component of induced stress tensor in the local coordinate of element " $\mathrm{m}$ " due to a unit continuous DD on element " $\mathrm{r}$ " in the " $\mathrm{kn}$ " direction occurring at time " $\Delta \mathrm{t}$ "; $S_{i j}^{s c}\left(\mathbf{x}^{m}-\boldsymbol{\chi}_{q}^{r}, \Delta t\right)$ is the "ij" component of induced stress tensor in the local coordinate of element "m" due to a unit continuous fluid source at vertex "q" on element "r" occurring at time; " $\Delta \mathrm{t}$ "; $P_{i j}^{d c}\left(\mathbf{x}_{p}^{m}-\chi^{r}, \Delta t\right)$ is 
the induced pore pressure at vertex "p" of element " $m$ " due to unit " $i j$ " component of continuous displacement discontinuity on element " $\mathrm{r}$ " occurring at time " $\Delta t$ "; $P^{s c}\left(\mathbf{x}_{p}^{m}-\chi_{q}^{r}, \Delta t\right)$ is the induced pore pressure at vertex "p" of element " $m$ " due to unit continuous fluid source at vertex " $\mathrm{q}$ " on element " $\mathrm{r}$ " occurring at time " $\Delta t$ "; $\mathrm{N}$ is the number of element. Note that the use of constant DDs across each element facilitates treatment of the hyper-singular integrations involved, while the fluid source intensities are assumed to vary linearly across each element [12].

Equations (5) are four linear algebraic equations in which the unknowns are increments of continuous three DDs and the fluid sources. The unknowns can be determined if the normal stress, two shear stresses, and the pressure on the fracture surfaces are defined. However, during the injection procedure, the pressure and the stresses on the fracture surfaces vary. Therefore, in addition to the three DDs increments and the fluid source increment, four left-hand sides in equation (5) will be added to the list of unknowns. First complimentary equation that can be used is the discretized form of the governing equation for fluid flow inside fracture (eq. (3)). The discretized form of the equation, with the help of Galerkin Finite element Method, is presented as follows:

$$
\begin{aligned}
& \mathbf{A}_{\mathbf{1}} \mathbf{p}+\mathbf{A}_{2} \mathbf{f}_{\mathbf{q}}=\mathbf{B} \\
& \mathbf{A}_{1}=\sum_{e=1}^{N} \int_{A_{e}} \nabla^{T} \mathbf{N}^{(e)} \frac{W^{3}}{12 \mu} \nabla \mathbf{N}^{(e)} d A_{e}, \quad \mathbf{A}_{2}=\sum_{e=1}^{N} \int_{A_{e}} \mathbf{N}^{(e) \mathrm{T}} \mathbf{N}^{(e)} d A_{e} \\
& \mathbf{B}=\left.\mathbf{N}^{(i n j)}\right|_{\left(\mathbf{x}_{i j j}\right)} Q_{i n j}(t)-\left.\mathbf{N}^{(e x t)}\right|_{\left(\mathbf{x}_{e x t}\right)} Q_{e x t}(t)-\sum_{e=1}^{N} \int_{A_{e}} \mathbf{N}^{(m) \mathrm{T}} \frac{\partial W}{\partial t} d A_{e} \\
& W\left(\mathbf{x}^{m}, s \Delta t\right)=D D_{33}^{m, s \Delta t}+W_{0}\left(\mathbf{x}^{m}\right)
\end{aligned}
$$

where $\mathbf{p}$ is a vector contains pressure magnitude at vertices of all elements, $\mathbf{f}_{\mathbf{q}}$ is vector contains fluid source or total leak off at vertices of all elements, $\mathbf{N}^{(e)}$ and $\mathbf{N}^{(m)}$ are the shape function vector of element "e" and "m" correspondingly, $A_{e}$ is area of element "e", $\mathbf{A}_{1}$ and $\mathbf{A}_{2}$ are global finite element matrices resulting from assembly of elemental level matrices defined in the equation (6), $\quad \mathbf{B}$ is finite element load vector that includes global injection/extraction and storage vector, $\left.\mathbf{N}^{(i n j)}\right|_{\left(x_{i i j}\right)}$ is a vector that has zero value at all nodes except at injection point that 
has unit value, $W_{0}$ is the initial crack aperture, and $W\left(\mathbf{x}^{m}, s \Delta t\right)$ is the total crack aperture at time $s \Delta t$ and at the middle of element " $\mathrm{m}$ " with $\mathbf{x}^{\mathrm{m}}$ location. Note that the same quadrilateral mesh for discontinuity method is also used for the spatial discretization in equation (6). In other words finite element mesh is same as the discontinuity mesh.

\subsection{Complementary relations}

In addition to the discretized form of fluid flow equation inside fractures, three more complimentary equations are employed to complete the equation set. These auxiliary equations are associated with the mechanical behavior of the discontinuities and are obtained by considering the intrinsic behavior of joints [20,21]. In particular, for zero effective stress on the discontinuity surface, the crack behaves as a hydraulic fracture, i.e., it is hydraulically and mechanically open. This means that the two surfaces of the crack are separated from each other, and the total stress on the crack surface is equal to the fluid pressure inside crack. Moreover, the shear stress on the crack surface is zero. Thus, for a discontinuity that behaves as a hydraulic fracture at time $s \Delta t$ and has a centroid location at $\mathbf{x}^{m}$, the three complementary equations are presented as:

$$
\sigma_{33}\left(\mathbf{x}^{m}, s \Delta t\right)=-p\left(\mathbf{x}^{m}, s \Delta t\right), \sigma_{13}\left(\mathbf{x}^{m}, s \Delta t\right)=0.0, \sigma_{23}\left(\mathbf{x}^{m}, s \Delta t\right)=0.0
$$

If a fracture has not opened completely, it can carry both compression and shear stresses. It is assumed that the shear traction on a crack surface is solely a function of the corresponding shear DD in the same direction. In addition to this, due to fracture asperities, the shear DD affects the net fracture aperture through crack dilation. For cracks with two surfaces in contact (in other words joints), the following constitutive relations serve as the three complementary equations:

$$
\begin{aligned}
& \sigma_{33}\left(\mathbf{x}^{m}, s \Delta t\right)=F_{n}\left(D D_{33}\left(\mathbf{x}^{m}, s \Delta t\right)\right)+F_{s}\left(D D_{13}\left(\mathbf{x}^{m}, s \Delta t\right), D D_{23}\left(\mathbf{x}^{m}, s \Delta t\right)\right), \\
& \sigma_{13}\left(\mathbf{x}^{m}, s \Delta t\right)=F_{1}\left(D D_{13}\left(\mathbf{x}^{m}, s \Delta t\right)\right) \\
& \sigma_{23}\left(\mathbf{x}^{m}, s \Delta t\right)=F_{2}\left(D D_{23}\left(\mathbf{x}^{m}, s \Delta t\right)\right)
\end{aligned}
$$


where $F_{n}$ is a function that relates joint opening/closure to normal effective stress (joint compression), $\quad F_{s}$ is a function that relates joint opening/closure to dilation effect, $F_{1}$ is the function that relates shear stress in direction 1 to shear $\mathrm{DD}_{13}$, and $F_{2}$ is the function that relates shear stress in direction 2 to shear $\mathrm{DD}_{23}$.

The normal behavior of joints is related to the amount of effective stress on the joint surface. According to the fundamentals of rock joint behavior [20], the constitutive model of joints in the normal direction is represented as follows:

$$
\begin{aligned}
& \boldsymbol{\sigma}_{\text {On joint surface }}^{\prime n+1}=\boldsymbol{\sigma}_{\text {On joint surface }}^{\prime n}+\left(\Delta \boldsymbol{\sigma}_{\text {Mechanical }}^{\prime n+1}+\boldsymbol{\sigma}_{\text {Dilation }}^{\prime n+1}\right) \\
& \Delta \boldsymbol{\sigma}_{\text {Mechanical }}^{n+1}+\boldsymbol{\sigma}_{\text {Dilation }}^{n+1}=\mathbf{K}_{\text {normal }}^{n+1} \times \Delta D D_{\text {normal }}^{n+1}-\mathbf{K}_{\text {normal }}^{n+1} \times D D_{\text {dil }}^{n+1} \\
& \Delta D D_{\text {normal }}^{n+1}=D D_{33}\left(\mathbf{x}^{m},(n+1) \Delta t\right)-D D_{33}\left(\mathbf{x}^{m}, n \Delta t\right) \\
& D D_{\text {dil }}^{n+1}=\left(\Delta D D_{\text {shear }}^{n+1}\right) \times \tan \phi_{\text {dil }}, \\
& D D_{\text {shear }}^{n+1}=\sqrt{\left(D D_{13}\left(\mathbf{x}^{m},(n+1) \Delta t\right)\right)^{2}+\left(D D_{23}\left(\mathbf{x}^{m},(n+1) \Delta t\right)\right)^{2}}
\end{aligned}
$$

where $\boldsymbol{\sigma}_{\text {On joint surface }}^{\prime n}$ is the effective normal stress on the joint surface at time $n \times \Delta t, \boldsymbol{\sigma}_{\text {Dilation }}^{\prime n}$ and $\Delta \boldsymbol{\sigma}_{\text {Mechanical }}^{\prime n}$ are the exerted effective normal stress on the joint surface due to dilation and incremental normal DD $\left(D D_{33}\right)$ at time $n \times \Delta t$ correspondingly, $\mathbf{K}_{\text {normal }}^{n}$ represents the normal stiffness of discontinuity at time $n \times \Delta t, \phi_{d i l}$ is the dilation angle of the joint, $D D_{\text {dil }}^{n}$ is the dilation of the joint due to total shear displacement discontinuity ( $D D_{\text {shear }}^{n}$ ) at time $n \times \Delta t$.

As shown by Amadei [20] and Bandis [21], when the effective stress is high enough (e.g., higher than $2 \mathrm{MPa}$ ), the joint behavior is completely linearly elastic and the normal stiffness can be assumed constant [21]. However, when the effective stress is near zero, the behavior is fully nonlinear and the normal stiffness can be defined by the following general nonlinear relation [22]:

$$
\boldsymbol{\sigma}_{\text {Mechanical }}^{\prime n+1} \times D D_{33}\left(\mathbf{x}^{m},(n+1) \Delta t\right)=\boldsymbol{\sigma}_{\text {Mechanical }}^{\prime 0} \times D D_{33}\left(\mathbf{x}^{m}, 0\right)=\text { Constant }
$$


The shear behavior of rock joints modeled using elasto-plastic behavior (with softening or hardening due to decrease or increase in the effective stress, respectively). The Mohr-Coulomb failure criterion is used to distinguish the beginning of the plastic behavior. Because the maximum tolerable shear depends on the amount of effective stress, the choice of softening or hardening is strongly dependent on the rate of change in the effective stress on the joint surface. If the effective stress decreases, the joint follows the softening branch during the post-elastic behavior. In contrast, if the effective stress increases, but permanent slippage on the joint surface is present, it follows the hardening branch. The behavior of the joint after experiencing shear slip (plastic behavior) is modeled by the slip-weakening model which is presented in following section.

\subsection{Slip-weakening model}

The slip-weakening model describes the progressive shear failure of pre-existing natural discontinuities under compression, and it was developed to simulate the post failure behavior of faults [23-25]. The model was used by Palmer and Rice [26] to study crack in over-consolidated clay specimens under simple shear but it can be applied to rock with appropriate parameters. They showed that the peak shear force is reached at a small shear displacement, after which the force required to produce further relative movements decreases continuously and approaches a residual value. The residual shear strength occurs when the relative shear slip along the crack overcomes a critical value $\left(\mathrm{DD}_{\mathrm{s}}^{*}\right)$. In order to implement the slip-weakening model in this work for modeling natural fractures, a linear law is used to represent the variation in the resistance parameters [27], as shown in Fig.1 where $c$ is cohesion of an element, $c^{p}$ is peak cohesion, $\varphi$ is friction angle of an element, $\varphi^{p}$ is peak friction angle, $\varphi^{f}$ is residual friction angle, and $\mathrm{DD}_{\mathrm{s}}^{*}$ is critical shear displacement discontinuity. In this setting, for a certain value of the relative shear slip along the crack, the friction angle decays from the peak to a residual value and the cohesion from the peak to zero. As a result, the shear strength decreases from the peak value to the residual value as a function of $\mathrm{DD}_{\mathrm{s}}$ for all the discontinuity elements. The sustained shear stresses on the slipping elements are always less than or equal to the shear strength. In addition, 
only the plastic value of the shear displacement $\left(\mathrm{DD}_{\mathrm{sp}}\right)$ is taken into account for the determination of the resistance parameters. In each step, the value of $\mathrm{DD}_{\mathrm{sp}}$ can be calculated as it is shown in Fig. 2 which is represented as follows:

$$
\begin{aligned}
& D D_{s p}^{n}=D D_{\text {shear }}^{n}-\sigma_{\text {shear }}^{n} / K_{s} \\
& \sigma_{\text {shear }}^{n}=\sqrt{\left(\sigma_{13}\left(\mathbf{x}^{m}, n \Delta t\right)\right)^{2}+\left(\sigma_{23}\left(\mathbf{x}^{m}, n \Delta t\right)\right)^{2}}
\end{aligned}
$$

where $K_{s}$ is the shear stiffness of discontinuity, $\mathrm{DD}_{\mathrm{sp}}^{\mathrm{n}}$ is the plastic shear displacement discontinuity of each element at time $n \times \Delta t, \mathrm{DD}_{\text {shear }}^{\mathrm{n}}$ is total shear displacement discontinuity at time $n \times \Delta t$, and $\sigma_{\text {shear }}^{\mathrm{n}}$ is total shear traction at time $n \times \Delta t$. As can be seen from Fig.2, $\sigma_{\mathrm{s}, \mathrm{el}}$ is the elastic part of shear traction on the element if the behaviour is assumed perfectly elastic and $\mathrm{DD}_{\mathrm{s}, \mathrm{el}}$ is the maximum elastic shear displacement discontinuity.

If $\mathrm{DD}_{\mathrm{sp}}$ is greater than the critical value $\left(\mathrm{DD}_{\mathrm{s}}^{*}\right)$, then the cohesion is zero and the friction angle is equal to its residual value. If $\mathrm{DD}_{\mathrm{sp}}$ is less than the critical value, the shear strength is calculated by linear law [27]. These statements are represented as follows:

$$
c^{n}=c^{p}\left(1-\frac{D D_{s p}^{n}}{D D_{s}^{*}}\right), \quad \varphi^{n}=\varphi^{p}\left(1-\frac{D D_{s p}^{n}}{D D_{s}^{*}}\right)+\varphi^{f} \frac{D D_{s p}^{n}}{D D_{s}^{*}}
$$

The slip-weakening modifications are applied to all elements that experienced a permanent slip and their properties are gradually changed by increasing the plastic shear DD.

\subsection{Solution steps}

By combining the complementary equations for hydraulic fracture or rock joints with the fluid flow equations inside the fracture (eq. (6)) and the discontinuities equation (eq. (5)), a unique solution can be obtained (i.e., eight equations and eight unknowns). The solution determines all components of displacement discontinuities (one normal component and two 
shear components), fluid source to rock matrix (leakoff), pressure inside crack, normal stress, and two shear stresses on each and every crack surfaces.

Throughout injection into the fracture system, each element (which represent part of a fracture) is either in a state of "open," "close," "stick," or "slip"; the element is considered closed for the latter two states. Element status may change between time steps and due to different constitutive relation shown in eqs. (7-10), element status should be determined to accurately simulate the behavior of a fracture network. At any time step " $k$ ", an initial value for the dilation is assumed for all elements and iteration is done to find an accurate dilation. At the end of each iteration step, the dilation is updated via equation (9); the iteration stops after the dilation value converges. There is an iteration inside dilation loop which determines element status in both normal and shear directions. If an element is in the "close" status, the normal stress and the shear stresses are defined by eq. (8), and if it is in the "open" status, they are defined by eq. (7). At the beginning of the solution procedure, it is assumed that all discontinuity elements are in the "close" and "stick" state, which provides the initial solution for the system of equations. Next, the resultant normal effective stress and shear stresses are calculated. If the effective stress is zero or negative, the normal status of the element is changed from "close" to "open." If an element is in "close" status, its status in shear direction is evaluated; if its shear stress is greater than the Mohr-Coulomb strength, the element status is changed from "stick" to "slip." In post elastic region, in addition to effective stress change, by taking into account slip-weakening behavior, the friction angle and cohesion of fracture elements gradually change. In other words, when an element's shear status has changed to "slip", the shear strength parameters (friction angle and cohesion) are updated based on the slip-weakening model. The entire process is iteratively repeated, until all the elements reach the same states for two subsequent iterations. Once the normal and shear states of all elements are determined, a new dilation is obtained by substituting the calculated shear displacements into eq. (9) and the procedure is repeated until the convergence condition is satisfied for the dilation.

The final solution step is checking the propagation status of all elements on the fracture front. If the calculated intensity factor in mode I or mode II of elements on any crack front is larger 
than the $K_{I c}$ and $K_{I I c}$ [28-30], then the injection rate is reduced and the whole procedure is repeated until the fracture toughness value of no element is exceeded.

Assuming that the stress condition around a crack tip is plane strain with the crack tip normal to the plane, the relations for the stress intensity factors for opening and shearing modes in threedimensional geometry based on Fig. 3 are presented [31, 32]:

$$
\begin{aligned}
& S I F_{I}=D D_{33} \frac{E}{4\left(1-v^{2}\right)} \sqrt{\frac{\pi}{2 d}} \\
& S I F_{I I}=D D_{13} \frac{E}{4\left(1-v^{2}\right)} \sqrt{\frac{\pi}{2 d}}
\end{aligned}
$$

where $\mathrm{SIF}_{\mathrm{I}}$ is calculated Mode I stress intensity factor and $\mathrm{SIF}_{\mathrm{II}}$ is calculated Mode II stress intensity factor.

\section{Example and analysis}

The DD model has been previously verified [33] so that our focus here is application to stimulation by injection and the mechanics of hydraulic fracture interaction with natural fractures with reference to permeability change and potential microseismicity. The example serves to illustrate the fundamental mechanisms when injecting into a fracture network. Fig.4 shows the problem configuration. The hydraulic (vertical) fracture $(300 \mathrm{~m} \times 100 \mathrm{~m})$ is surrounded by two sets of natural fractures on either side. Each natural fracture is $20 \mathrm{~m} \times 20 \mathrm{~m}$ square and is discretized by 16 quadrilateral elements $(5 \mathrm{~m} \times 5 \mathrm{~m})$. The middle point of each natural fracture is $10 \mathrm{~m}$ away from the main fracture in $x$ direction. The middle point of each natural fracture is 40 $\mathrm{m}$ away from each other in $y$ - and $z$-directions. Note that the minimum and the maximum distance, in the $x$-direction, of the natural fractures from the main fracture are $5 \mathrm{~m}$ and $15 \mathrm{~m}$, respectively. The natural fractures are oriented so that they can be critically sheared along their dip, however they are initially stable and may become reactivated after hydraulic stimulation. Table 1 presents the properties used to simulate the problem. The injection rate is adjusted during the simulation to maintain the hydraulic (vertical) fracture on the verge of propagation. 
To better describe the effect of natural fractures on the hydraulic fracture, first we consider injection into it (Fig. 5) without any natural fracture in place.

The hydraulic fracture is discretized with 300 quadrilateral elements $(10 \mathrm{~m} \times 10 \mathrm{~m})$, and 341 nodes. The fluid injection rate is prescribed in the middle of the fracture where a well is placed in the mesh. Small time steps of 1.0 min duration are chosen to capture the nonlinearity and the transition behavior of the elements from joint to hydraulic fracture.

Initially, the system is in equilibrium under the in-situ stress and the fracture is closed at a residual fracture aperture under the action of the normal stress. As injection continues, the elements are pressurized and opened under the action of fluid pressure. Figure 6 shows the injection rate profile that maintains the stability of the hydraulic fracture (without the presence of natural fractures) and prevents it from propagation. The injection rate is constant $\left(0.135 \mathrm{~m}^{3} / \mathrm{s}\right)$ for the first $26 \mathrm{~min}$ and then it suddenly decreases to $0.05 \mathrm{~m}^{3} / \mathrm{s}$. The sudden decrease is due to the fact that after $24 \mathrm{~min}$, elements on the edge of the fracture begin to open; therefore, their aperture increases dramatically and the fracture is ready to propagate.

Transformation of the elements from joints to hydraulic fractures at different time steps is shown in Fig. 7. The figure shows the transition of the elements from hydraulically open but mechanically closed (joint) to those that are hydraulically and mechanically open. The opening of the vertical fracture begins after 4.0 min of injection and the whole hydraulic fracture is open after $11 \mathrm{~min}$ (except for a narrow band at the fracture tips). After $24 \mathrm{~min}$, the elements on the top and bottom edge (closest to the injection point) begin to open. At this time, the injection rate is automatically decreased to prevent the Mode I stress intensity factor (SIF) from exceeding the fracture toughness.

Figure 8 shows Mode I propagation status of the edge elements after 4, 11, 24, and 60 minutes of injection. Prior to $26 \mathrm{~min}$, the ratio of the calculated SIF to the fracture toughness is about 0.55 . However, after $26 \mathrm{~min}$ of injecting at a constant rate of $0.135 \mathrm{~m}^{3} / \mathrm{s}$, the SIF reached near the critical value and to prevent propagation, the injection rate is decreased to maintain the near equilibrium status of the fracture $\left(0.95<K_{I} / K_{I c}<1.0\right)$.

The hydromechanical behavior of the vertical fracture during the injection process and fracture reopening is summarized by examining the pressure profile of the injection point. Figure 
9 shows that for times less than 2 min, the pressure rapidly increases until the closed fracture begin to reopen. Immediately after the central fracture elements opened completely, the pressure trend drastically changes with a rapid decrease. This is an indication that some fracture elements have opened and the permeability of fracture has significantly increased. The pressure profile continues to decrease until $11 \mathrm{~min}$, the time at which almost all elements on the fracture surface (except the elements on the edge) are open. Next, the pressure builds up until the edge elements closest to the injection well are forced to open and the fracture reaches the propagation stage (at 26 min). At this time, as can be seen in Fig.6, the injection rate decreases and the pressure at the injection point continues to increase slowly to ensure the fracture is maintained just below equilibrium.

To evaluate the effect of the injection on the stability of natural fractures and to study their interactions with the main hydraulic (vertical) fracture, the fracture system of Fig.4 was modeled. The shear status of the fracture system during injection procedure is shown in Fig.10. As can be seen from the figure, fractures A, B, C, and D did not experience any permanent slip for $14 \mathrm{~min}$. However, after $15 \mathrm{~min}$ of injection into the hydraulic fracture, natural fracture A (and its mirror fractures) begins slipping on its edges, and the slipping continues in different natural fractures (at their edges) until the fracture C begins to slip. After 17 min, the Mode II SIF of fracture A exceeds the fracture toughness indicating the potential for propagation of the NF to connect with the main fracture. The shear slip on natural fractures results from pore pressure diffusion and the mechanical interaction between the natural and vertical fractures. Slip is observed on the edges of the natural fractures where they are closets to the vertical fracture. These are the locations of the maximum value of the exerted shear stress on the natural fracture due to the opening of vertical fracture, which forces the natural fractures to slip. The magnitude of shear slip and the slip area on these fractures are in the range of $0.1 \mathrm{~mm}$ and $25 \mathrm{~m}^{2}$, respectively. According to Hanks [34] and McGarr [35], the seismic moment due to slip amount of " $\mathrm{u}$ " over the slip area "A" can be described as $M_{0}=\int_{A} G \times u \times d A$, where $\mathrm{G}$ is the shear modulus of the rock. The magnitude of a seismic event generated by the seismic moment $M_{0}$ can 
be estimated as $M=\frac{2}{3} \times \log \left(M_{0}\right)-10.7$. Therefore, the resulting microseismicity events would have magnitudes of around -0.5 .

The opening distribution of the hydraulic fracture is shown in Fig.11; comparison with Fig. 7 shows that in the presence of natural fractures, it is easier to open the hydraulic fracture as it requires less effort to be completely open (i.e., the same region opens earlier in time). The behavior is due to the softening effect of natural fractures.

The pressure, aperture, normal effective stress, and shear DD profile at the midpoint of natural fractures A, B, C, and D are shown in Fig. 12 to Fig. 15, respectively. Three major mechanisms operate simultaneously on those fractures: 1) stress redistribution because of the opening of the hydraulic fracture and poroelastic stress, 2) pore pressure diffusion because of leakoff from the hydraulic fracture into the surrounding rock matrix/fracture, and 3) dilation of the natural fractures in response to the action of the far field stress and the stresses induced by other fractures. The effects of each mechanism on the fracture aperture, effective normal stress, pressure, and shear DD of a particular orientation of the natural fractures is presented in Table 2. Note that, for example, owing to the stress redistribution, the natural fracture aperture decreases while the effective stress, fluid pressure, and shear DD increase.

As shown in Fig. 12 to Fig. 15, there are generally three regions (shown in the figures) of behavior for the natural fractures. In region 1, the behavior of the natural fractures is dominated by the stress redistribution due to opening of hydraulic fracture. All natural fractures (fractures A, B, C, and D) initially exhibit a decrease in their aperture and an increase in their effective stress (i.e., the opening of the hydraulic fracture closes the natural fractures). Subsequently, the fracture aperture begins to increase as the effective stress decreases because of the net effects of diffusion and dilation. In region 1, the pressure and total shear DD both continuously increase.

In region 2, the natural fracture behavior is dominated by the transition to hydraulic fracture elements (from mechanically closed to mechanically open). The time duration of region 2 for the natural fracture A is comparable to the time the hydraulic fracture continues to open. From Fig.11, it is clear that after 5 minutes, the region inside of the vertical fracture located in 
front of natural fracture A has changed its state causing a sudden change in the behavior of natural fracture A. The same comparison for the other natural fractures suggests the same scenario. Thus, region 2 is observed on all natural fractures and is a result of the opening mode of the hydraulic fracture or in other words, the stress shadow effect. This effect is more intense for natural fractures $\mathrm{A}$ and $\mathrm{B}$ as compared to fractures $\mathrm{C}$ and $\mathrm{D}$ since the former opens more. Region 3 in the natural fractures behavior appears when the effect of pore fluid diffusion process dominates, and the fracture aperture, pressure, and shear DD increase while the effective stress decreases. In this region, the main fracture has completely opened. As a consequence, around the natural fractures matrix pore pressure increases at a higher rate, the fracture aperture and shear DD continue to increase as the effective stress decreases, eventually causing slip events on natural fractures with possible microseismicity.

\section{Conclusions}

The process of shear deformation and shear-slip or "hydro shearing" caused by hydraulic stimulation of a fractured rock has been numerically modeled by developing a DD/finite element method. The model simulates the opening of a closed natural fracture into a hydraulic fracture and also predicts natural fracture responses using a non-linear joint model with a slip-weakening law. The analysis considers full coupling between stress and fluid diffusion. In order to demonstrate the versatility of this method and to illustrate some fundamental mechanisms associated with injection into a network of fractures, a system of hydraulic and natural fractures was modeled. The effect of slip and opening of closed fractures on downhole pressure profile was studies and occurrence of microseismic events was assessed based on natural fracture slip calculations.

The modeling results show that natural fractures tend to initially close as the main hydraulic fractures opens with injection, but they open soon after and the degree of their opening generally depends on the stress state (fracture orientation) and the injection rate. As the injection into the hydraulic fracture continues and the closed fracture elements open up, the downhole pressure drops until the entire fracture opens. Subsequently, the pressure builds up again as injection continues while the fracture is maintained in equilibrium (no propagation). Injection below the 
critical rate tends to increase the fracture conductivity without creation of additional surface area for the hydraulic fracture.

The analysis of the natural fracture response surrounding the hydraulic fracture clearly reveals reactivation of natural fractures with potential seismic events. There are three major mechanisms that significantly affect the natural fracture deformation and slip namely, the stress shadow, the pore pressure diffusion into the matrix, and the dilation of the natural fracture itself. These processes cause the natural fracture opening to be a transient phenomenon with decreasing and increasing episodes. For the system studied here, slip is first observed on the edges of the natural fractures where they are closets to the main vertical hydraulic fracture and where the induced shear stresses are the maximum due to the opening of the main hydraulic fracture. The magnitude of shear slip and the slip area on these fractures are in the range of $0.1 \mathrm{~mm}$ and $25 \mathrm{~m}^{2}$, respectively. Thus, the resulting microseismic events have magnitudes of around -0.5. Although, the slip on the natural fractures can potentially contribute to seismic activity, its contribution to permeability enhancement depends on whether or not they propagate to connect and to form a "hydraulically" connected network with the main fracture. When the natural fracture system is not connected to the main flow path, the MEQ information may overestimate the so called stimulated reservoir volume.

\section{Acknowledgements}

This project was supported by the U.S. Department of Energy Office of Energy Efficiency and Renewable Energy under Cooperative Agreement DE-PS36-08GO1896. This support does not constitute an endorsement by the U.S. Department of Energy of the views expressed in this publication. 


\section{REFERENCES}

[1] Ghassemi A. A review of some rock mechanics issues in geothermal reservoir development. Geotech Geol Eng 2012; 30:647-64.

[2] Warpinski NR. Hydraulic fracturing in tight, fissured media. SPE J Petrol Tech 1991; 43:146-54.

[3] Geertsma J, Klerk Fd. A rapid method of predicting width and extent of hydraulically induced fractures. J Petrol Tech 1969; 21:1571-81.

[4] Perkins TK, Kern LR. Widths of hydraulic fractures. J Petrol Tech 1961; 13: 937-49.

[5] Brady JL, Withers RJ, Fairbanks TD, Dressen D. Microseismic monitoring of hydraulic fractures in Prudhoe Bay. SPE Annual Technical Conference and Exhibition. New Orleans, Louisiana; Sep. 1994.

[6] Branagan PT, Cipolla CL, Lee SJ, Yan L. Case History of hydraulic fracture performance in the naturally fractured Paludal Zone: the transitory effects of damage. Low Permeability Reservoirs Symposium. Denver, Colorado: Jan. 1987.

[7] Warpinski NR, Teufel LW. Influence of geologic discontinuities on hydraulic fracture propagation (includes associated papers 17011 and 17074 ). SPE J Petrol Tech 1987; 39:209-20.

[8] Asgian MI. A numerical study of fluid flow in a deformable, naturally fractured reservoir: The influence of pumping rate on reservoir response. The 29th U.S. Symposium on Rock Mechanics (USRMS), Minneapolis, Minnesota; Jun. 1988.

[9] Swenson D, Beikmann M. An implicitly coupled model of fluid flow in jointed rock. The 33th U.S. Symposium on Rock Mechanics (USRMS), Santa Fe, New Mexico; Jun. 1992. 
[10] Lee BT, Ghassemi A. Shear slip and permeability change caused by injection/extraction in a fractured reservoir. 45th U.S. Rock Mechanics Symposium, San Francisco, California; Jun. 2011.

[11] Tao Q, Ghassemi A, Ehlig-Economides CA. A fully coupled method to model fracture permeability change in naturally fractured reservoirs. Int J Rock Mech Min Sci 2011;48:259-68.

[12] Zhou XX, Ghassemi A, Cheng AHD. A three-dimensional integral equation model for calculating poro- and thermoelastic stresses induced by cold water injection into a geothermal reservoir. Int J Numer Anal Meth Geomech 2009; 33:1613-40.

[13] Biot MA. General Theory of Three-Dimensional Consolidation. J Appl Phys 1941; 12:15564.

[14] Rice JR, Cleary MP. Some basic stress diffusion solutions for fluid-saturated elastic porous media with compressible constituents. Rev Geophys 1976; 14:227-41.

[15] Polubarinova-Kochina, P.Y., Theory of ground water movement, Translated from the Russian edition by J. M. Roger de Wiest. 1962, Princeton, N.J.: Princeton University Press.

[16] Ghassemi A, Roegiers JC. A three-dimensional poroelastic hydraulic fracture simulator using the displacement discontinuity method. 2nd North American rock mechanics symposium. Montreal, Quebec, Jun. 1996.

[17] Vandamme LM, Roegiers JC. Poroelasticity in hydraulic fracturing simulators. SPE J Petrol Tech 1990; 42:1199-203.

[18] Carvalho JL, Curran JH. Three-dimensional displacement discontinuity solutions for fluidsaturated porous media. Int J Solids Struct 1998; 35:4887-93.

[19] Curran JH, Carvalho JL. A displacement discontinuity model for fluid-saturated porous media. 6th ISRM Congress, Montreal, Canada; Aug. 1987. 
[20] Amadei B, Saeb S. Constitutive models of rock joints. Proceedings of the International Symposium on Rock Joints, Loen, Norway, N. Barton and O. Stephansson (eds), Balkema, Rotterdam, 1990: 581-94.

[21] Bandis SC. Mechanical properties of rock joints. Proceedings of the International Symposium on Rock Joints, Loen, Norway, N. Barton and O. Stephansson (eds), Balkema, Rotterdam, 1990: 125-40.

[22] Goodman RE. The mechanical properties of joints. 3rd International Congress of International Society of Rock Mechanics. Denver, Colorado, 1974.

[23] Day SM. Three-dimensional simulation of spontaneous rupture: The effect of nonuniform prestress. Bull Seism Soc Amer 1982;72:1881-902.

[24] Ida Y. Cohesive force across the tip of a longitudinal-shear crack and griffith's specific surface energy. J Geophys Res 1972;77:3796-805.

[25] Wawersik WR, Brace WF. Post-failure behavior of a granite and diabase. Rock Mech Rock Eng 1971;3:61-85.

[26] Palmer AC, Rice JR. The growth of slip surfaces in the progressive failure of overconsolidated clay. Proc Roy Soc Lon A Math Phys Sci 1973;332:527-48.

[27] Allodi A, Castelli M, Scavia C. Implementation of the slip-weakening model in a displacement discontinuity method based numerical technique. In: Brebbia CA, editor. Boundary Elements XXIV. UK.2002.

[28] Griffith AA. The phenomena of rupture and flow in solids. Phil Trans Roy Soc Lond Ser A $1921 ; 221$.

[29] Irwin GR. Analysis of stresses and strains near the end of a crack traversing a plate. J Appl Mech 1957; 24:361-364. 
[30] Roegiers JC, Zhao XL. Rock fracture tests in simulated downhole conditions. The 32nd U.S. Symposium on Rock Mechanics (USRMS), Norman, Oklahoma; Jul. 1991.

[31] Aliabadi MH. Boundary element formulations in fracture mechanics. Appl Mech Rev 1997;50:83-96.

[32] Martha LF, P. A. Wawrzynek, Ingraffea AR. Arbitrary crack representation using solid modeling. Eng Comput 1993;9:63-82.

[33] Safari M.R. , Ghassemi A. 3D Poroelastic analysis of natural fracture response to variable injection/extraction rates. 44th U.S. Rock Mechanics Symposium and 5th U.S.-Canada Rock Mechanics Symposium, Salt Lake City, Utah; Jun. 2010.

[34] Hanks TC, Kanamori H. A moment magnitude scale. J Geophys Res Solid Earth 1979;84:2348-50.

[35] McGarr A, Spottiswoode SM, Gay NC, Ortlepp WD. Observations relevant to seismic driving stress, stress drop, and efficiency. J Geophys Res Solid Earth 1979;84:2251-61. 


\section{List of Figures}

Fig.1 Linear slip-weakening law is chosen for (a) friction angle $\varphi(b)$ and cohesion c.

Fig.2 Elastic and plastic tangential DD on a discontinuity element in residual condition.

Fig.3 Four-node quadrilateral element at crack edge.

Fig.4 Discretized geometry of hydraulic and natural fracture network; there are two sets of natural fractures with a center to center distance of $40 \mathrm{~m}$ in the $\mathrm{y}$ - and $\mathrm{z}$ - direction, and $10 \mathrm{~m}$ in $\mathrm{x}$ directions.

Fig.5 Discretized hydraulic fracture without natural fracture in place.

Fig.6 Injection profile during first hour of stimulation to maintain hydraulic (vertical) fracture stability.

Fig.7 Opening of vertical fracture elements during injection process. Black elements are joints (hydraulically open, mechanically closed) and grey elements are hydraulic fractures (hydraulically and mechanically open).

Fig.8 Propagation status of edge element in Mode I propagation.

Fig.9 Pressure profile at injection point.

Fig. 10 Shear states of natural fractures at different time steps, black indicates slipped elements.

Fig.11 Opening of a fracture system with natural fractures, grey indicates open element.

Fig.12 Midpoint pressure profiles of fractures A, B, C, and D.

Fig.13 Midpoint aperture profiles of fractures A, B, C, and D.

Fig.14 Midpoint effective stress profiles of fractures A, B, C, and D. 
Fig.15 Midpoint shear DD profiles of fractures A, B, C, and D. 


\section{List of Tables}

Table 1. Parameters used to model a fracture in Barnett shale formation.

Table 2. Effects of each mechanism on behavior of natural fracture (NF) with respect to particular orientation. 
Table 1. Parameters used to model a fracture network in Barnett shale environment.

\begin{tabular}{|c|c|c|c|}
\hline Shear modulus & $(\mathrm{Pa})$ & $8.30 \times 10^{9}$ & (1203 ksi) \\
\hline Drained Poisson's ratio & & 0.25 & \\
\hline Undrained Poisson's ratio & & 0.46 & \\
\hline Biot coefficient & & 0.96 & \\
\hline Base permeability & $\left(\mathrm{m}^{2}\right)$ & $1.00 \times 10^{-17}$ & (10 micro Darcy) \\
\hline Initial joint aperture & (m) & $1.00 \times 10^{-4}$ & (0.004 in) \\
\hline Minimum joint aperture & $(\mathrm{m})$ & $1.00 \times 10^{-5}$ & $(0.0004 \mathrm{in})$ \\
\hline Stress in X direction & (MPa) & 43.00 & $(6236 \mathrm{psi})$ \\
\hline Stress in Y direction & $(\mathrm{MPa})$ & 39.00 & (5656 psi) \\
\hline Stress in $\mathrm{Z}$ direction & $(\mathrm{MPa})$ & 56.50 & (8194 psi) \\
\hline Reservoir pore pressure & $(\mathrm{MPa})$ & 28.30 & (4104 psi) \\
\hline Rock density & $\left(\mathrm{kg} / \mathrm{m}^{3}\right)$ & 2650.00 & $(0.115 \mathrm{psi} / \mathrm{ft})$ \\
\hline Fluid density & $\left(\mathrm{kg} / \mathrm{m}^{3}\right)$ & 1000.00 & $(0.0433 \mathrm{psi} / \mathrm{ft})$ \\
\hline Fluid viscosity & $\left(\mathrm{N} . \mathrm{s} / \mathrm{m}^{2}\right)$ & $3.00 \times 10^{-4}$ & $(0.3 \mathrm{cp})$ \\
\hline Initial pumping rate & $(\mathrm{L} / \mathrm{s})$ & 135.00 & $(51 \mathrm{bbl} / \mathrm{min})$ \\
\hline Peak friction angle & & $30^{\circ}$ & \\
\hline Residual friction angle & & $20^{\circ}$ & \\
\hline Peak cohesion & $(\mathrm{MPa})$ & 0.70 & (101 psi) \\
\hline Residual cohesion & $(\mathrm{MPa})$ & 0.00 & $(0.00 \mathrm{psi})$ \\
\hline Dilation angle & & $3^{\circ}$ & \\
\hline Maximum aperture due to dilation & (m) & $5.00 \times 10^{-4}$ & (0.02 in) \\
\hline Critical value for shear DD, D* & $(\mathrm{m})$ & $5.00 \times 10^{-3}$ & $(0.2$ in $)$ \\
\hline Linear normal stiffness & $(\mathrm{MPa} / \mathrm{m})$ & $2.00 \times 10^{4}$ & $(9350 \mathrm{ksi} / \mathrm{ft})$ \\
\hline Linear shear stiffness & $(\mathrm{MPa} / \mathrm{m})$ & $2.00 \times 10^{4}$ & $(9350 \mathrm{ksi} / \mathrm{ft})$ \\
\hline Mode I critical fracture toughness & $\left(\mathrm{MPa}^{0} \mathrm{~m}^{0.5}\right)$ & 1.50 & $\left(1.65\right.$ psi.in $\left.^{0.5}\right)$ \\
\hline Mode II critical fracture toughness & $\left(\mathrm{MPa}^{\mathrm{m}} \mathrm{N}^{0.5}\right)$ & 2.00 & $\left(1.82\right.$ psi.in $\left.^{0.5}\right)$ \\
\hline
\end{tabular}


Table 2. Effects of each mechanism on behavior of natural fracture (NF) with respect to particular orientation.

\begin{tabular}{|c|c|c|c|c|}
\hline Mechanisms & $\begin{array}{c}\text { Impact on NF } \\
\text { aperture }\end{array}$ & $\begin{array}{c}\text { Impact on } \\
\text { effective normal } \\
\text { stress of NF }\end{array}$ & $\begin{array}{c}\text { Impact on } \\
\text { pressure inside of } \\
\text { NF }\end{array}$ & $\begin{array}{c}\text { Impact on shear } \\
\text { DD of NF }\end{array}$ \\
\hline Stress redistribution & Decrease & Increase & Decrease & Increase \\
\hline Diffusion & Increase & Decrease & Increase & Increase \\
\hline Fracture dilation & Increase & Increase & Decrease & Increase \\
\hline
\end{tabular}



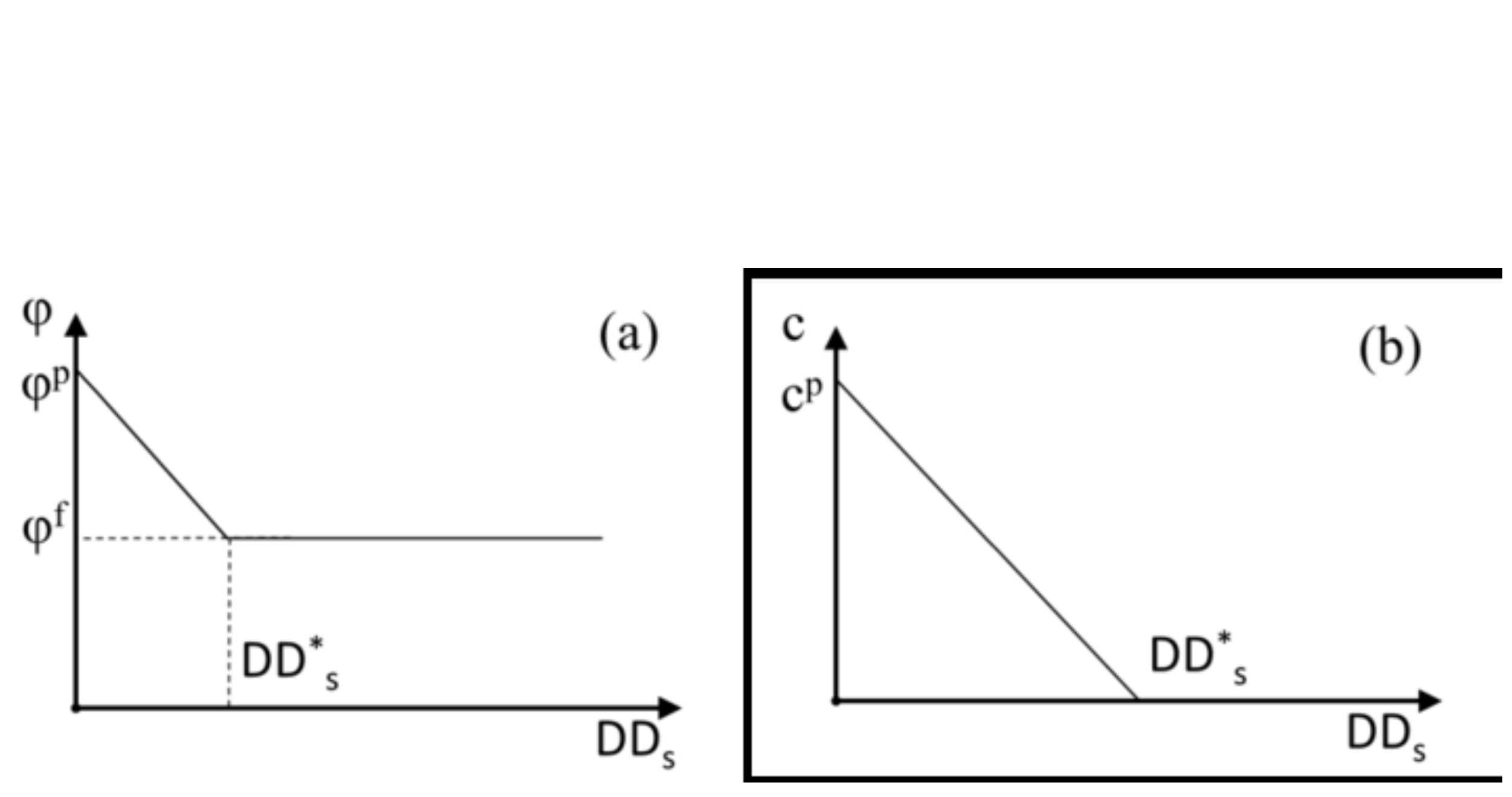
Local

Coordinates

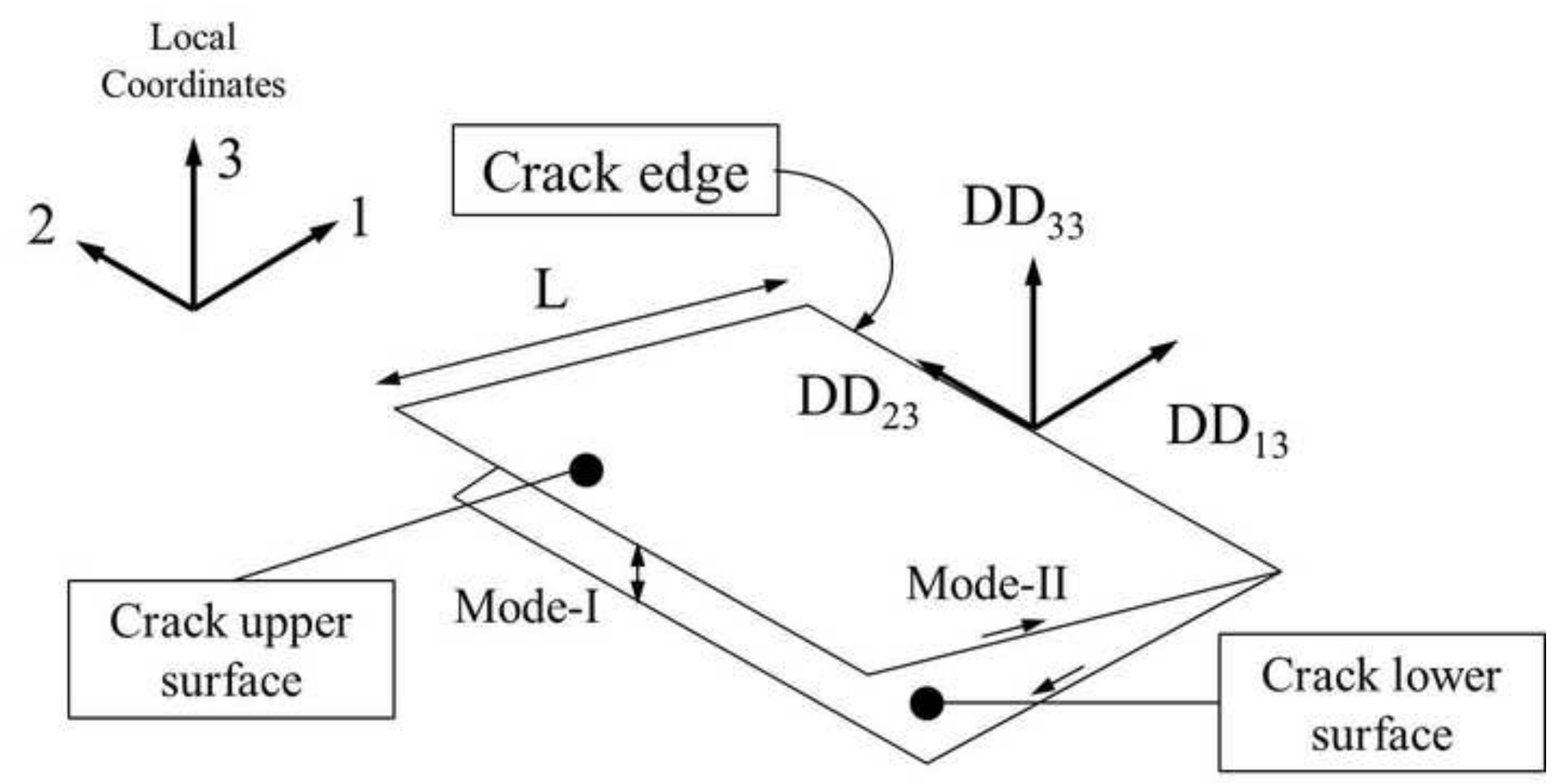




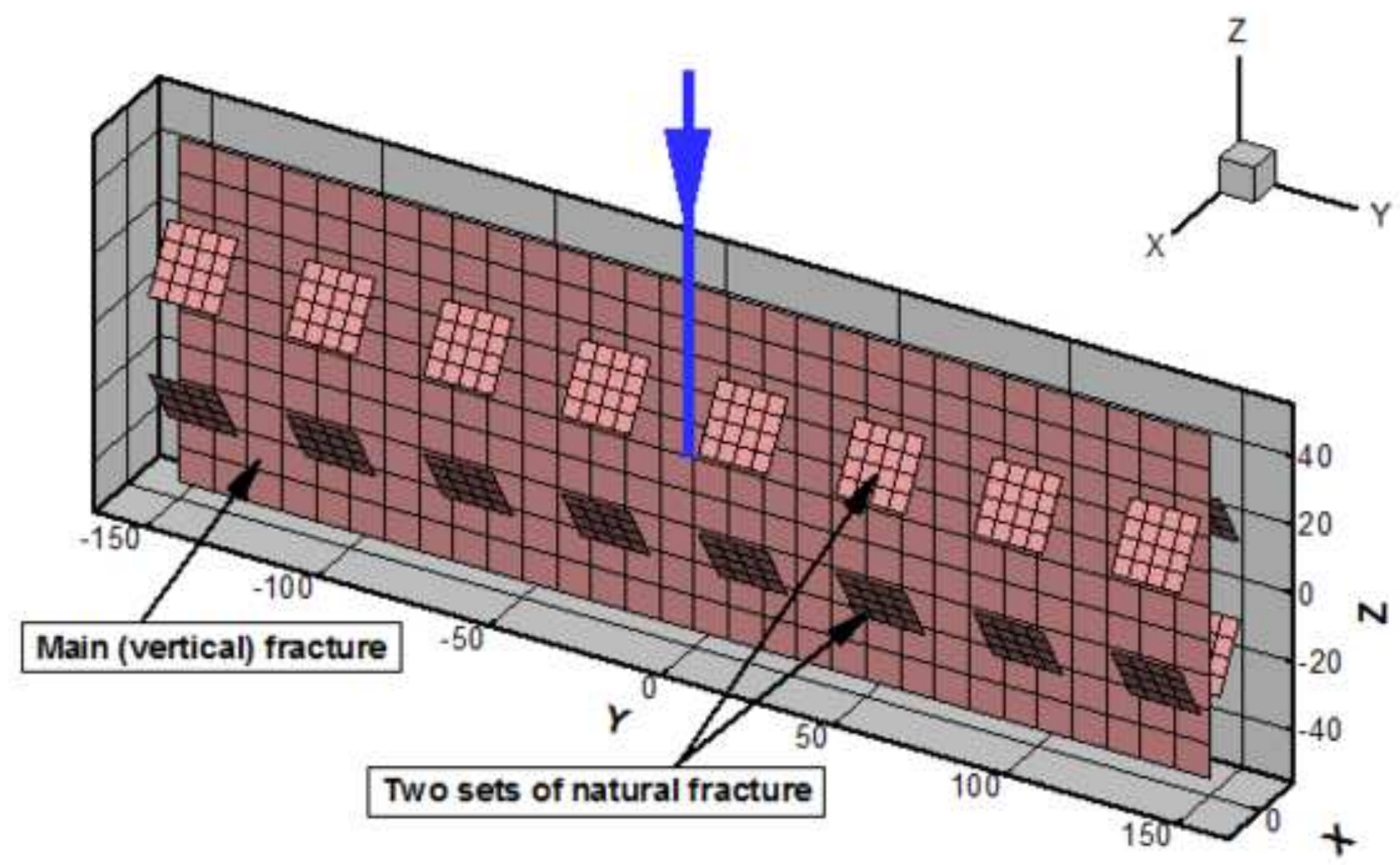




\section{Figure 5

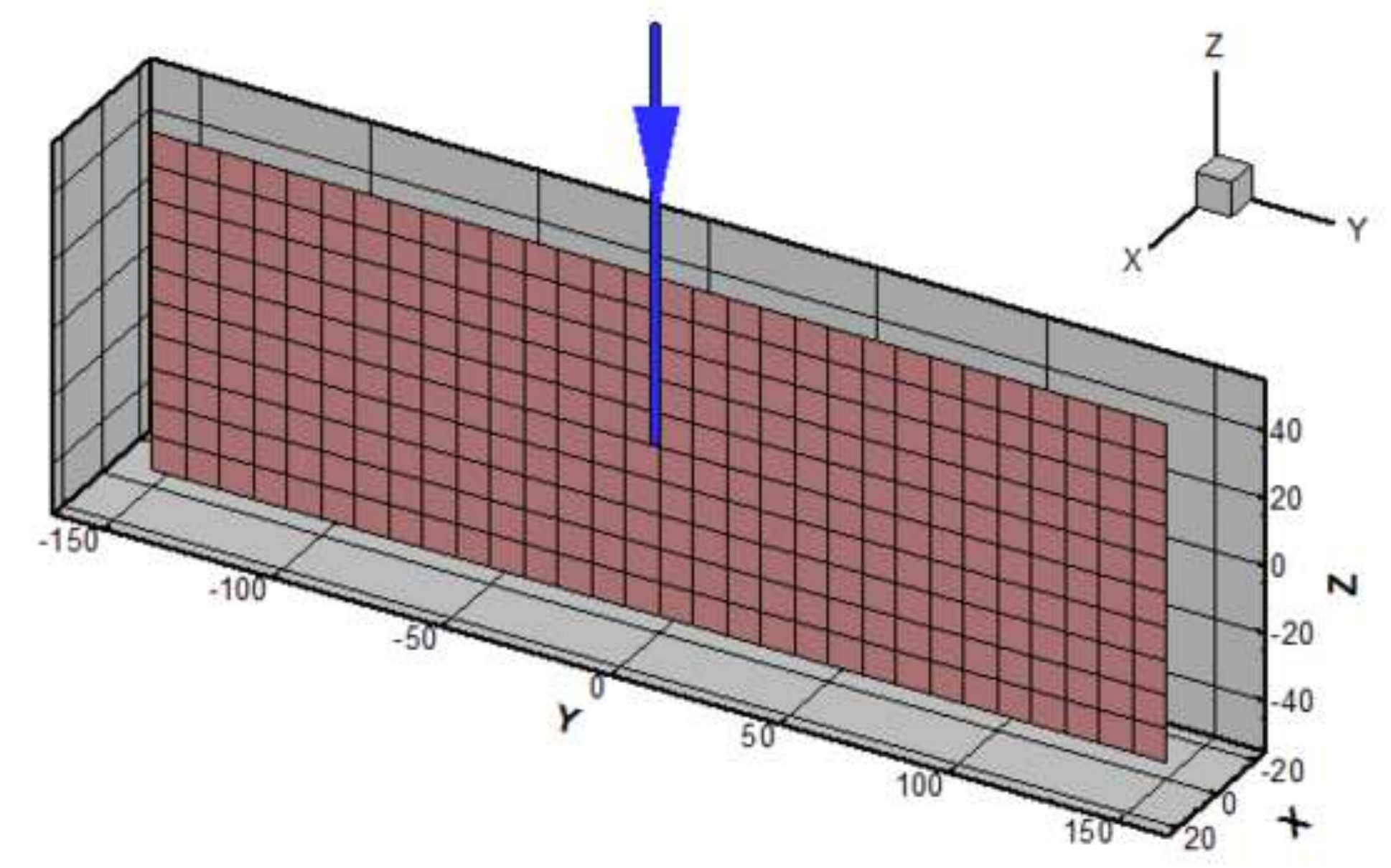




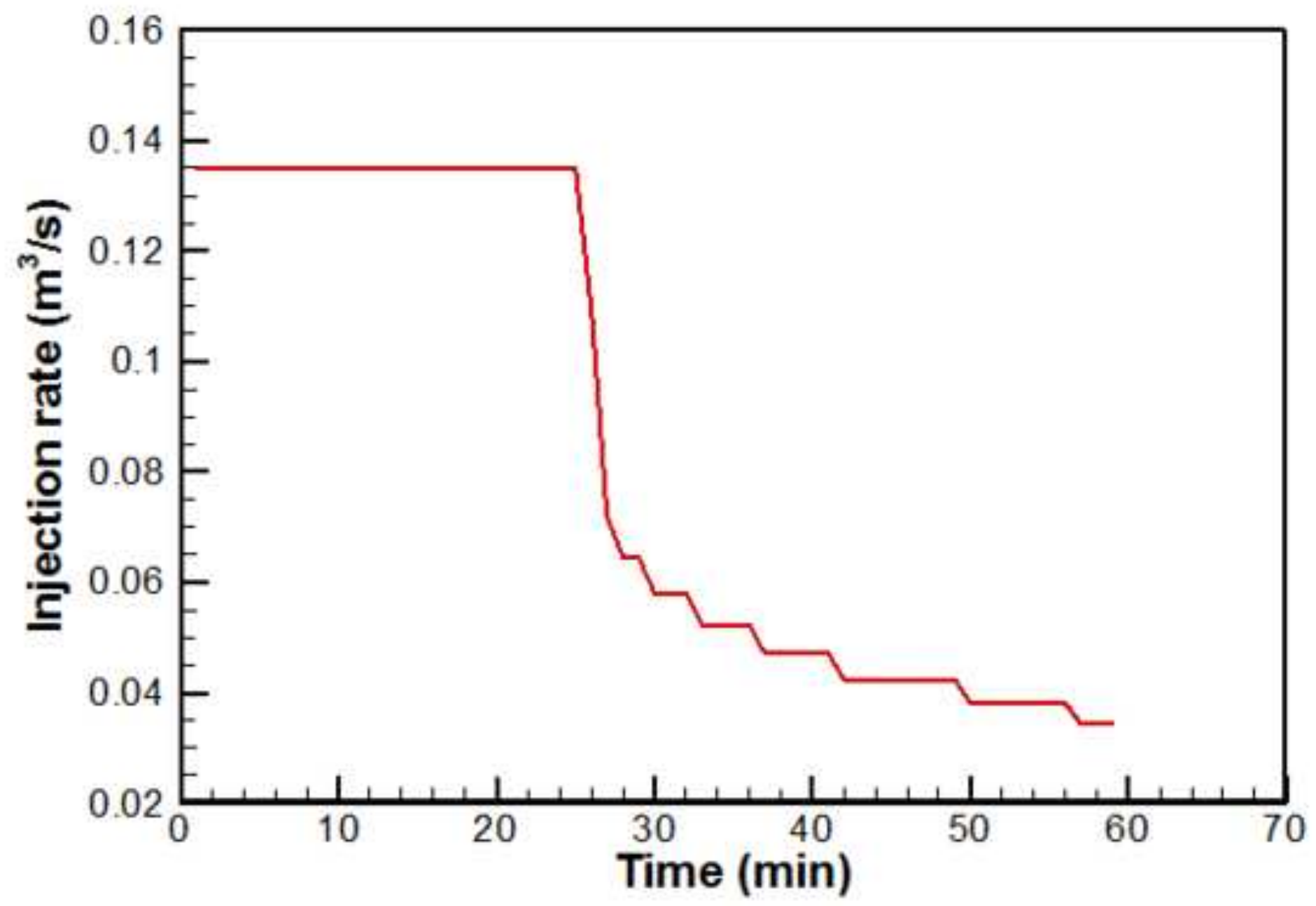



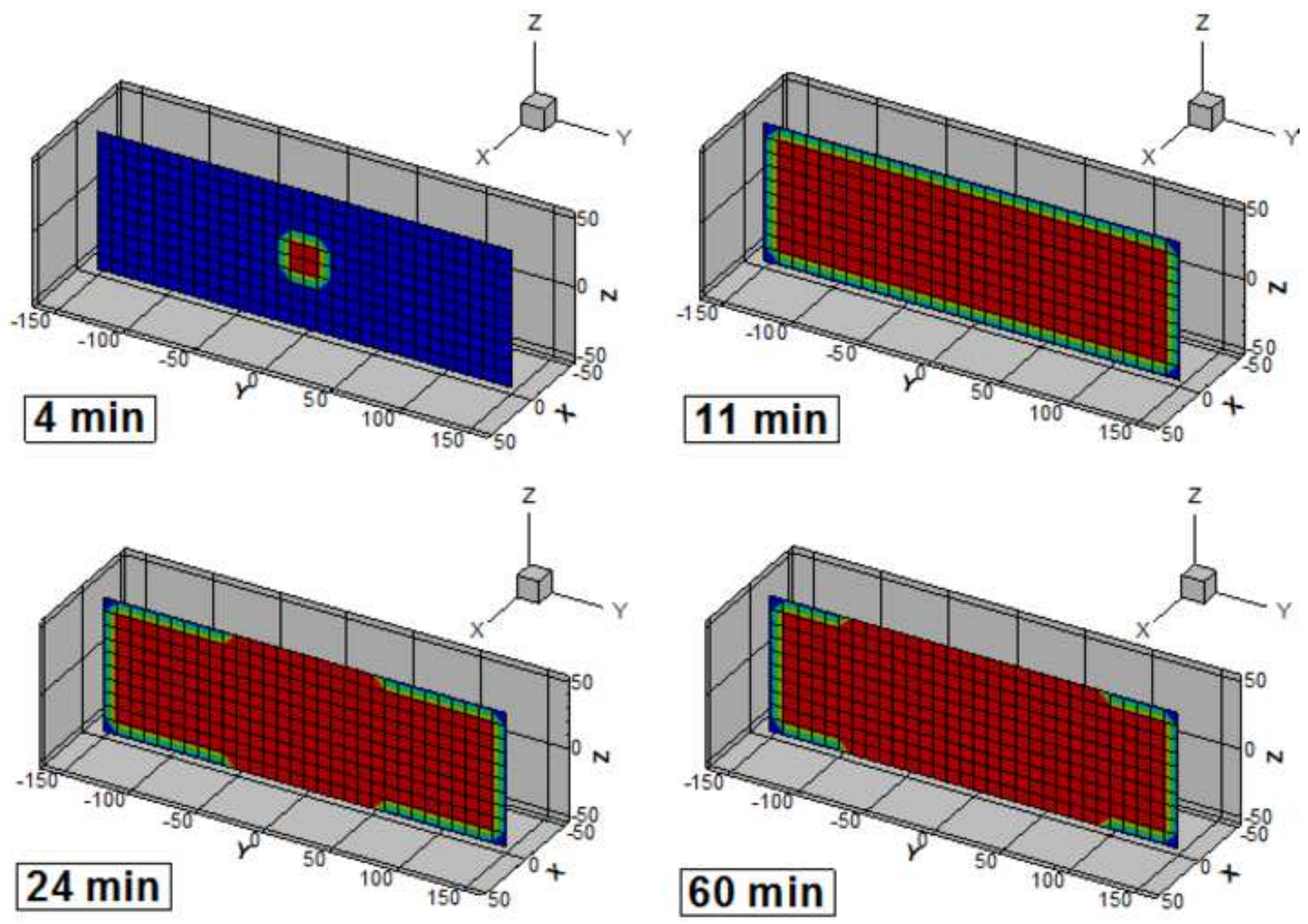

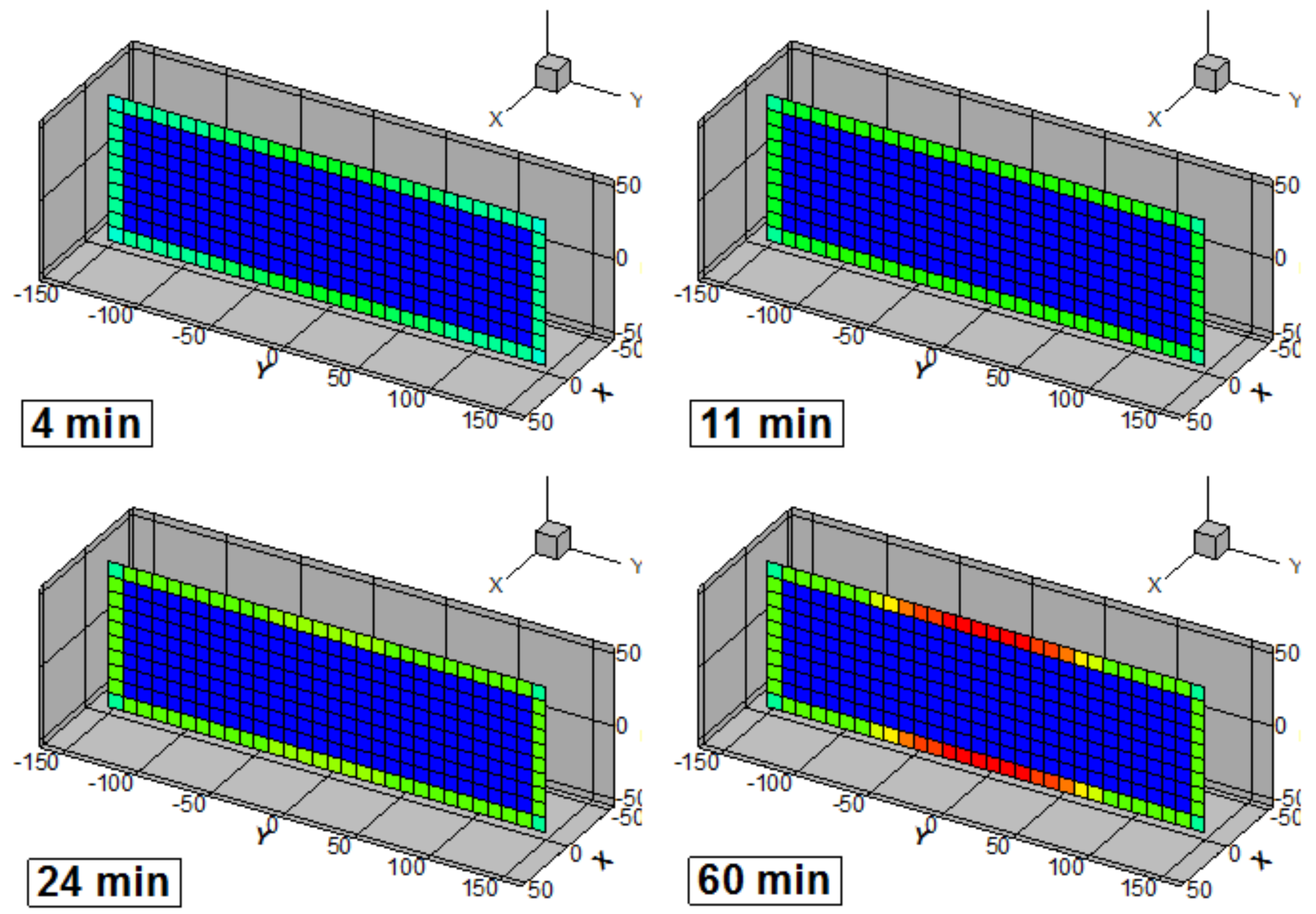

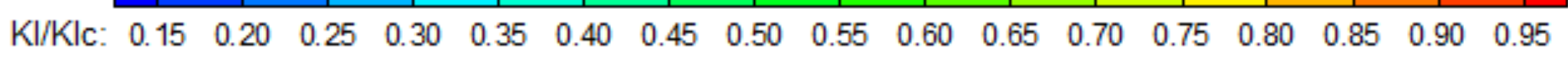




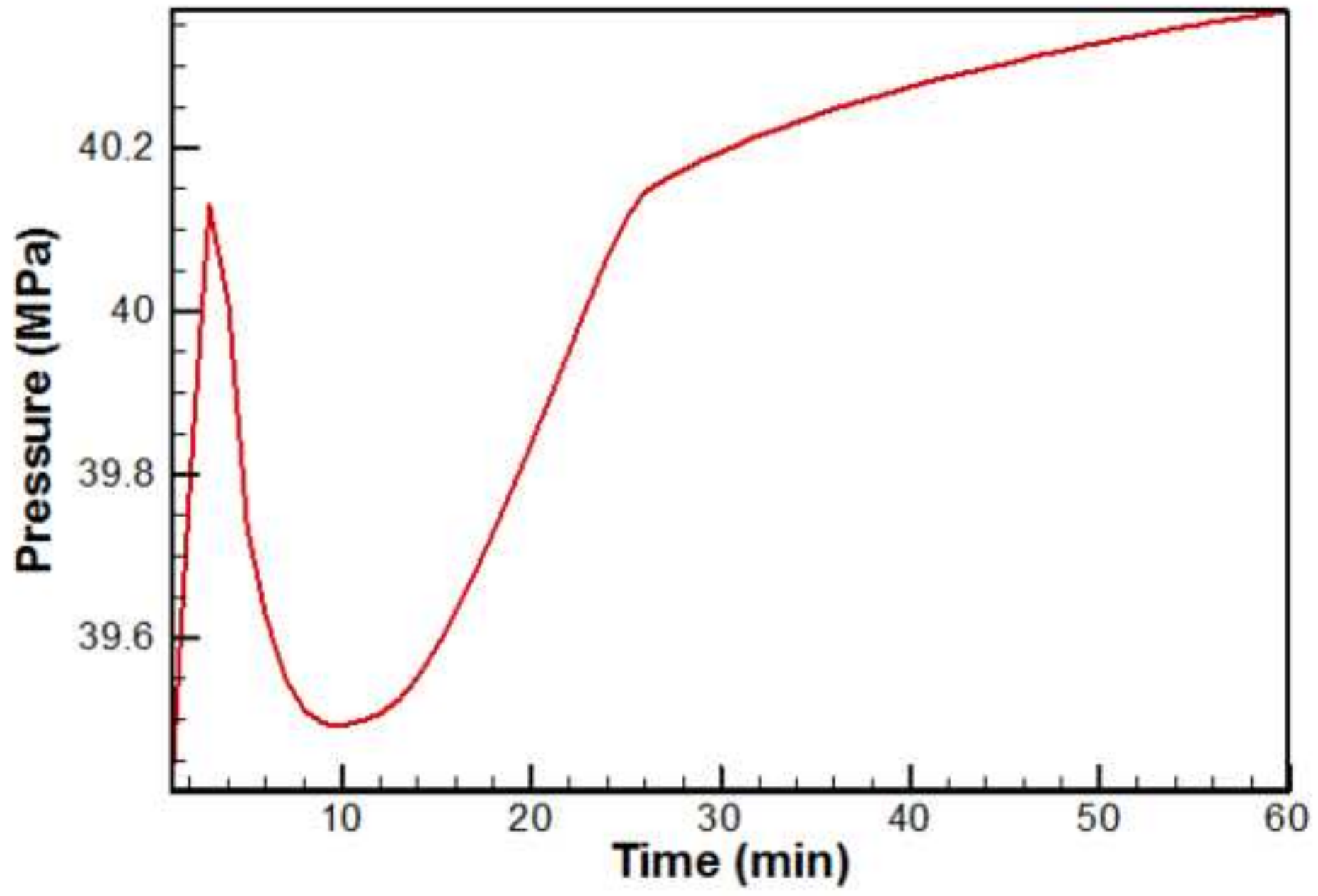


$14 \mathrm{~min}$

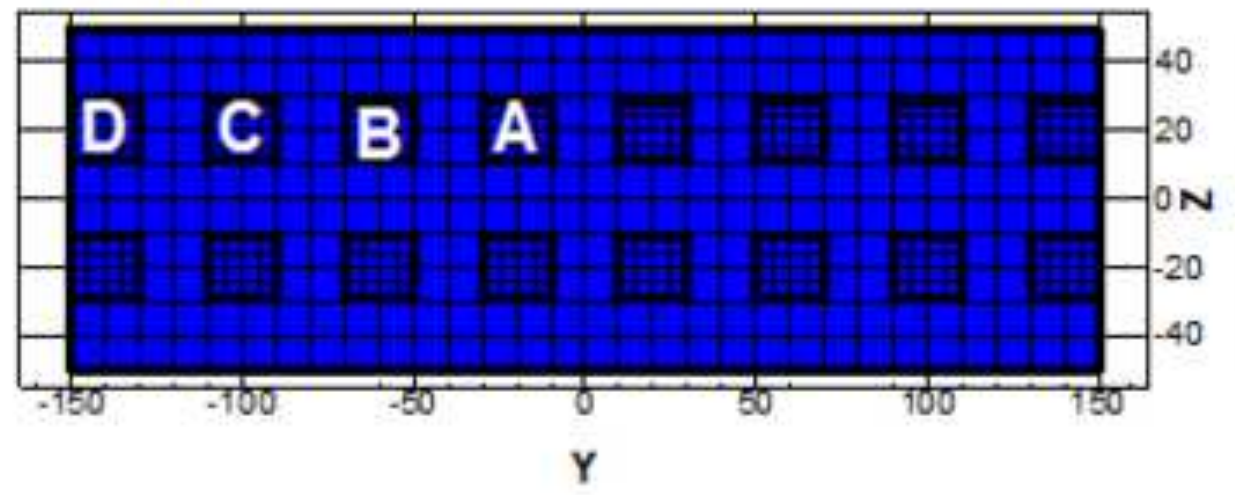

$16 \mathrm{~min}$

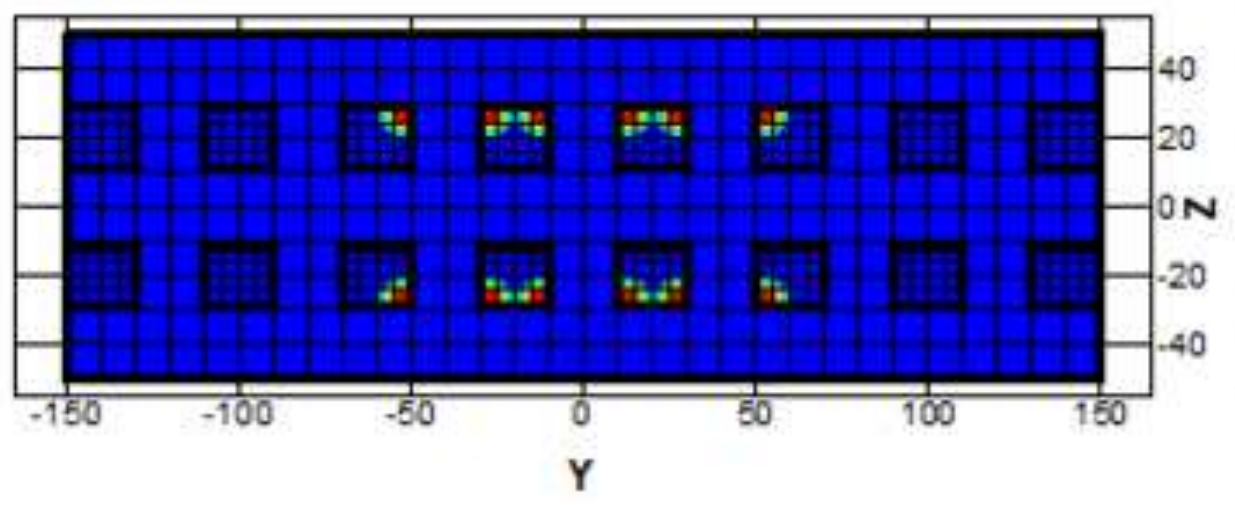

$15 \mathrm{~min}$

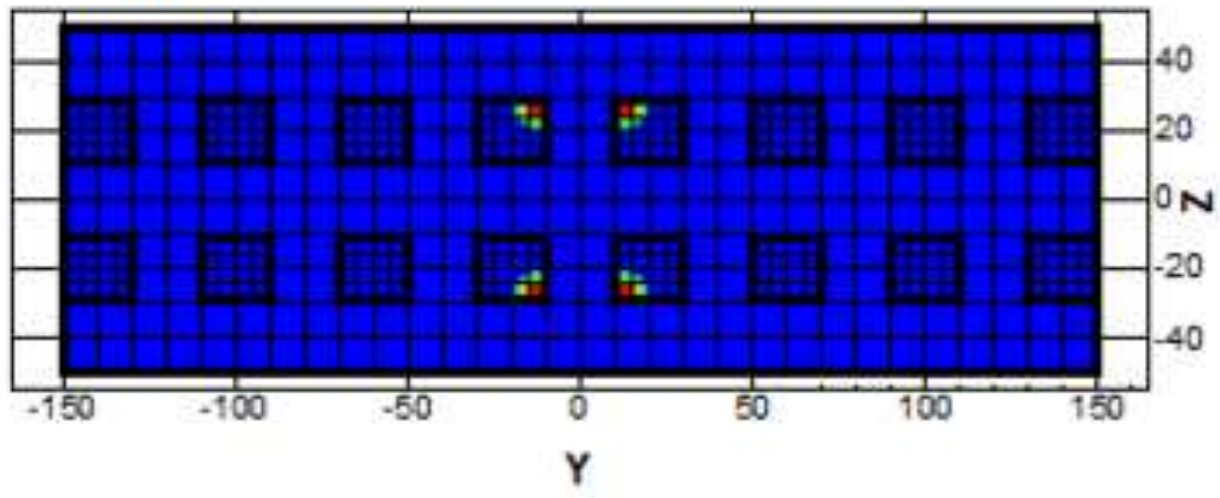

$17 \mathrm{~min}$

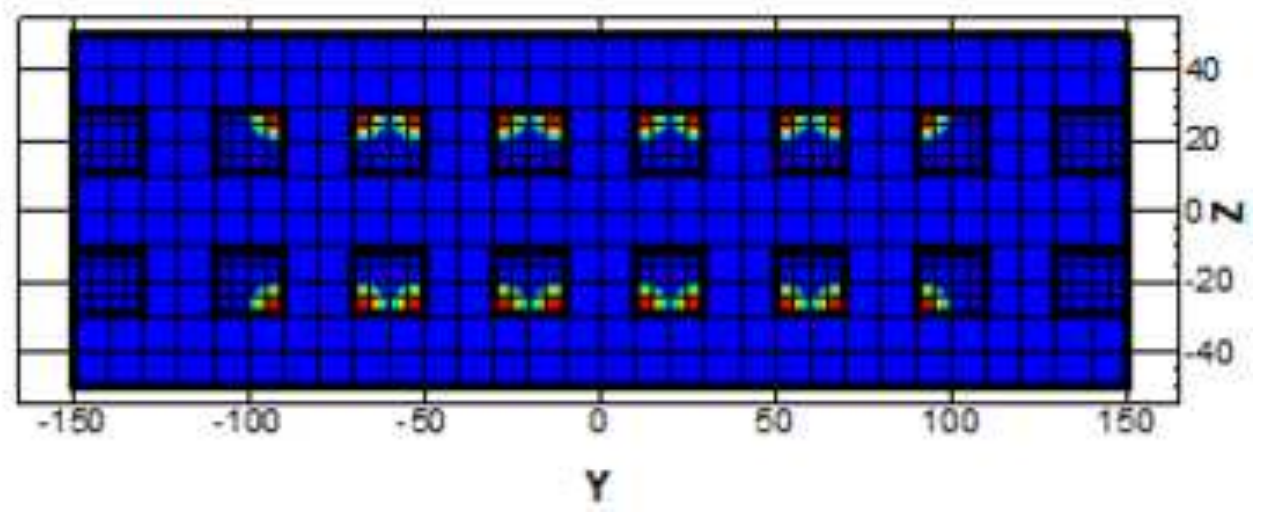




\section{$5 \mathrm{~min}$}

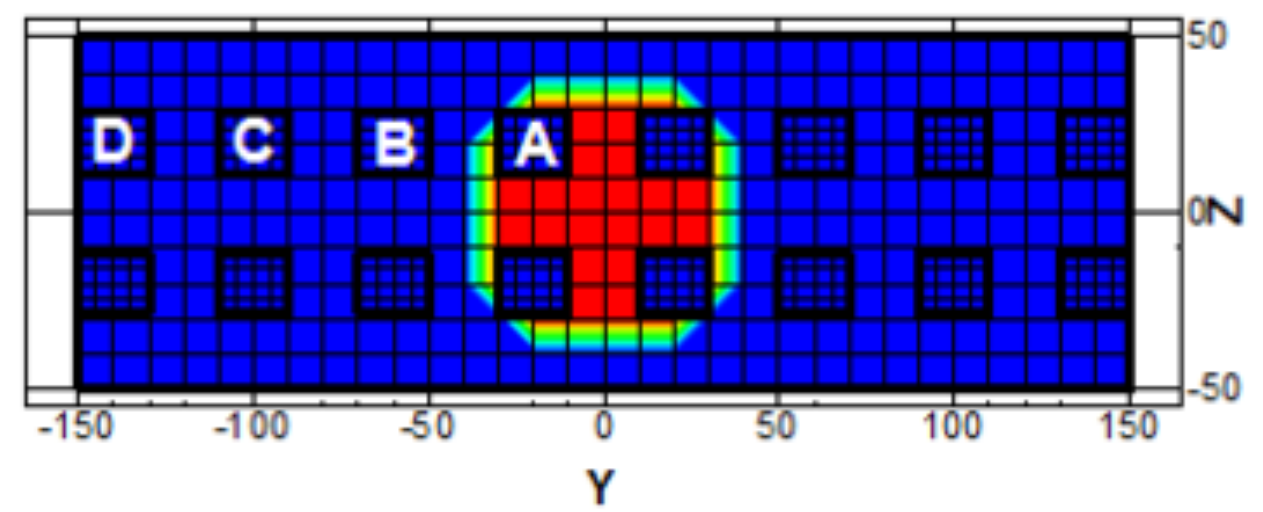

\section{$8 \mathrm{~m}$ in}

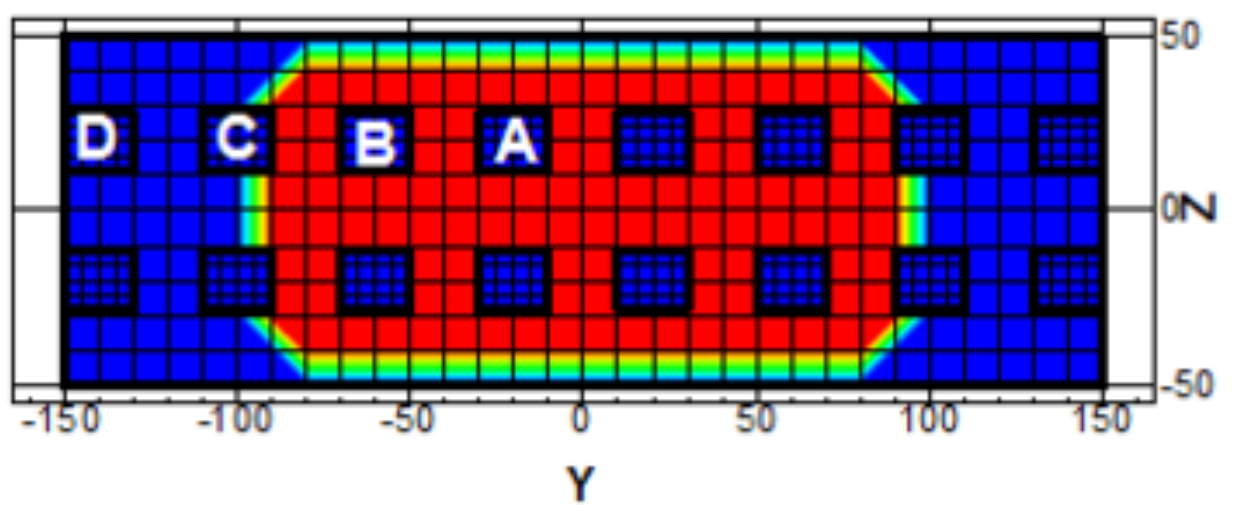

$7 \mathrm{~m}$ in

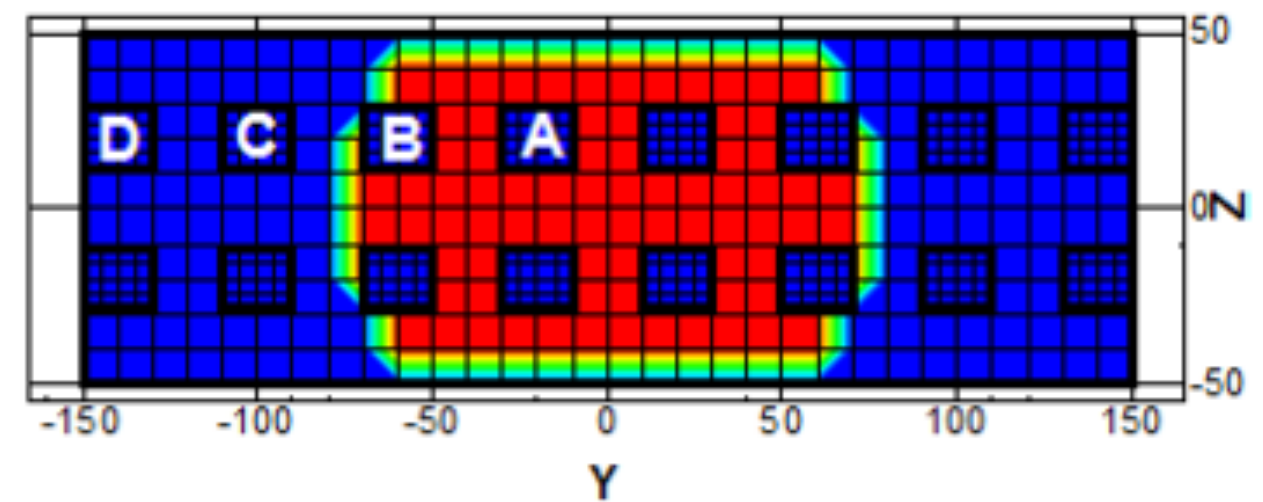

$10 \mathrm{~min}$

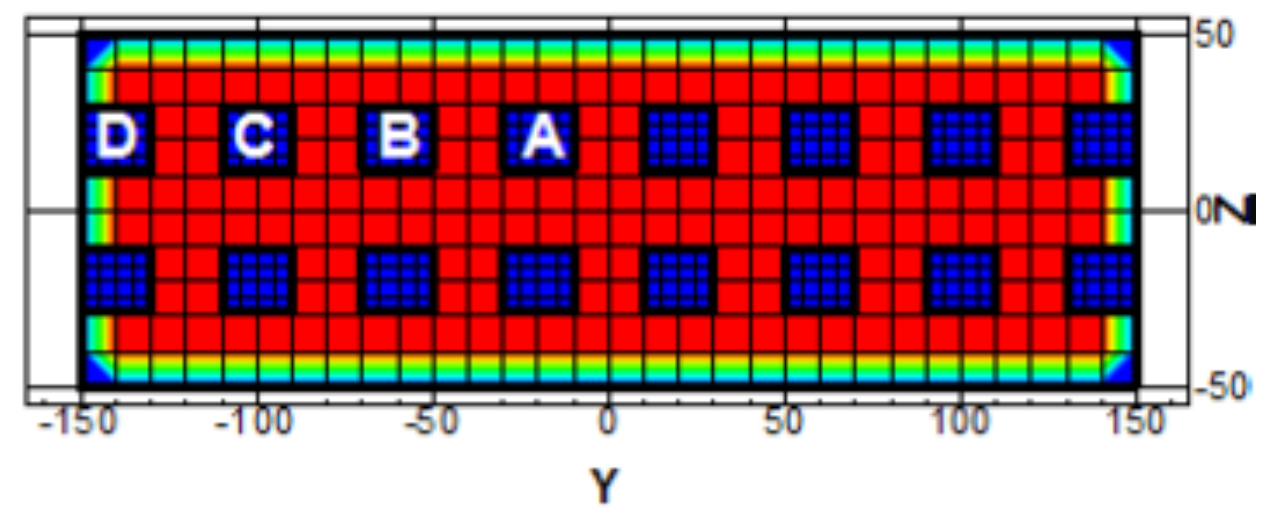



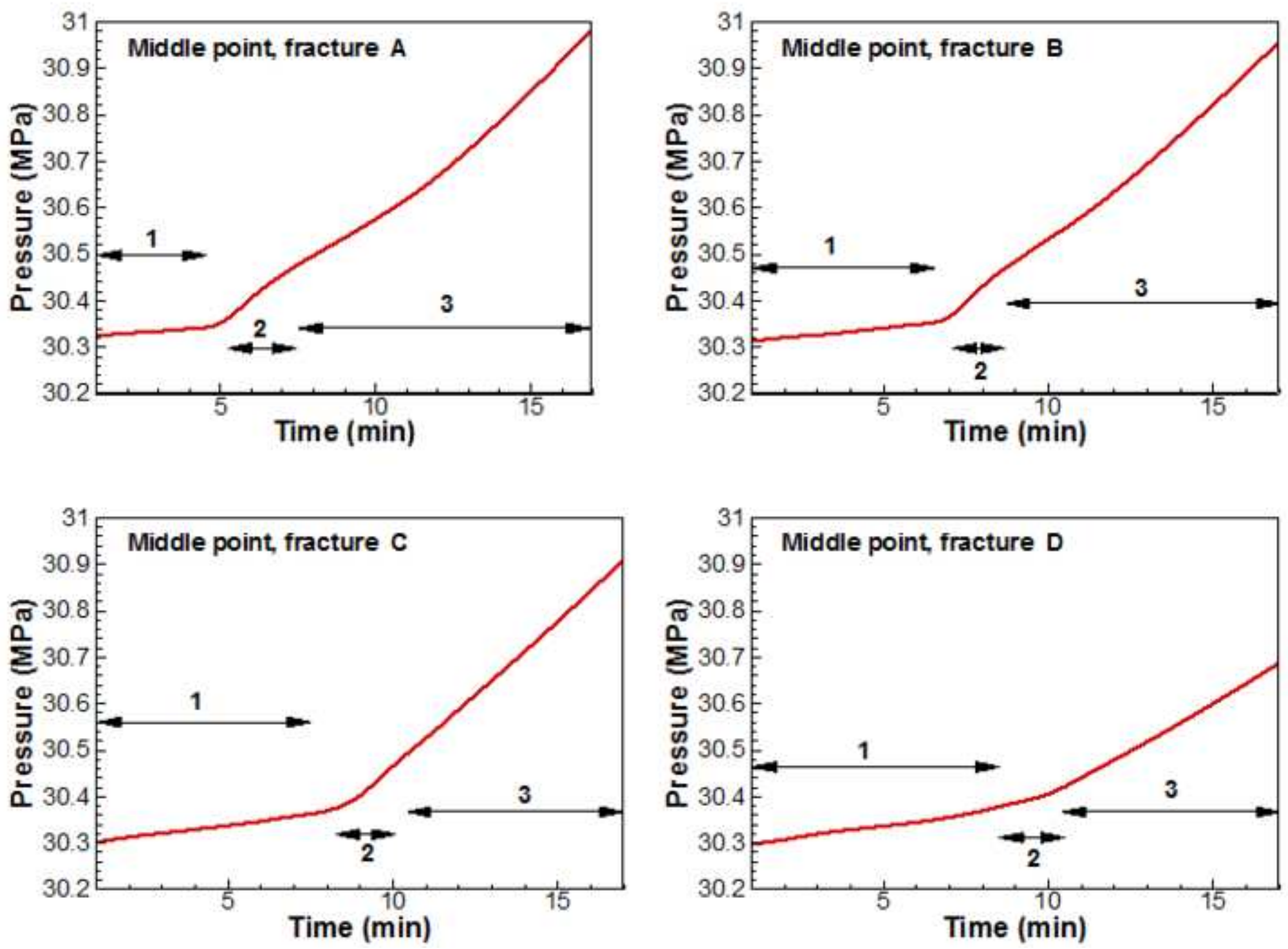

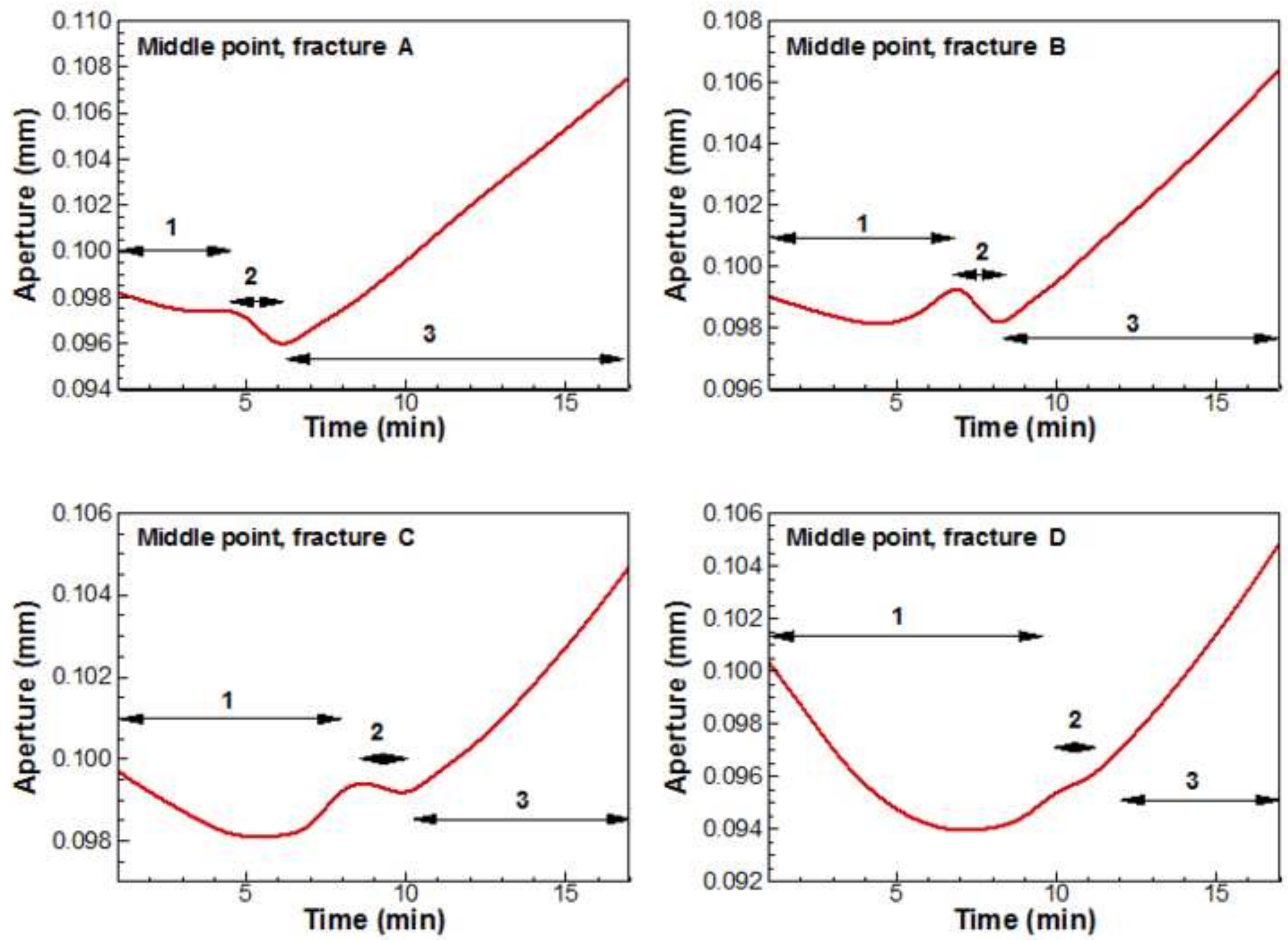

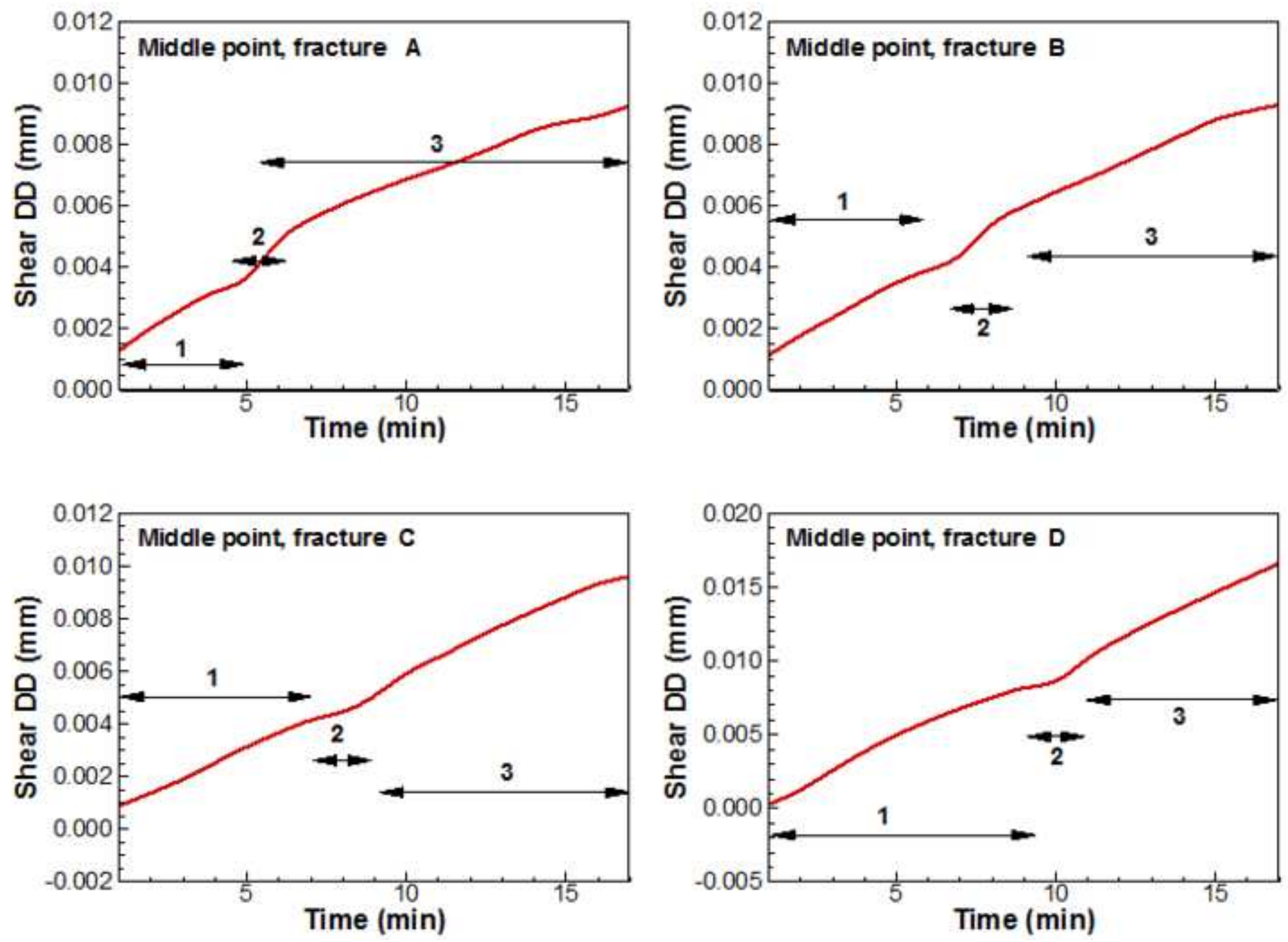